\title{
Energy Harvesting Device
}

\section{Driton Salihu}

Division of Industrial Electrical Engineering and Automation Faculty of Engineering, Lund University 


\title{
Energy Harvesting Device
}

\author{
Driton Salihu \\ Division of Industrial Electrical Engineering and Automation \\ Lund University
}

Supervisor: Gunnar Lindstedt, Lund University

Ranjith Dharmasiri, ABB Discrete Automation \& Motion Robotics

Examiner: Ulf Jeppsson, Lund University

October 2016, Lund 
This thesis evaluates the concept of Energy Harvesting as a power source for a serial measurement board used by ABB robots. A background study of possible energy harvesters is included, where the main focus is put on the overall function and what parameters determine the maximum generated power and efficiencies.

Furthermore, a design of a physical proof of concept for solar as an Energy Harvesting Source is examined. The design consists of solar cells as Harvester, a Power Management Integrated Circuit for managing power requirements of the host system and an Energy Storage to be used when the source is not available.

Two solar technologies, amorphous silicon cells and gallium arsenide cells, are examined and compared. The output characteristics are measured to determine their performance at different indoor illuminances.

Charge- and discharge-times for a supercapacitor bank, consisting of six parallel connected supercapacitors, is examined.

The host system, i.e. the serial measurement board consumes a maximum power of 1 $\mathrm{mW}$. The designed Energy Harvesting System used in this thesis generates a maximum power of $1.73 \mathrm{~mW}$ at a light intensity of 600 Lux. A three-week long test is done with the prototype to demonstrate that this method is capable of providing the desired power. 


\section{Acknowledgments}

First, I would like to express my sincere gratitude to my supervisor Ranjith Dharmasiri at ABB for his guidance and support. I value the fact that he always had time to answer my questions and queries.

This master's thesis was done in conjunction with ABB Robotics in Västerås, Sweden. I would also like to thank the department manager Per Carlsson for the opportunity and for the interest and support during my thesis work.

A thanks to my supervisor at LTH, Gunnar Lindstedt and the examiner, Ulf Jeppsson for the opportunity and valuable ideas for the report.

Last but definitely not least, my deepest gratitude goes to my family and friends for their unfailing support and love. 


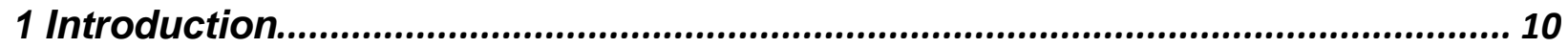

1.1 Background

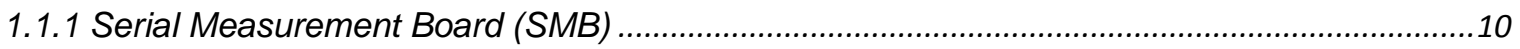

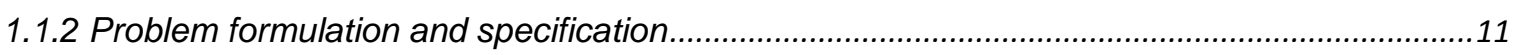

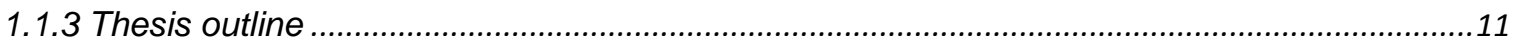

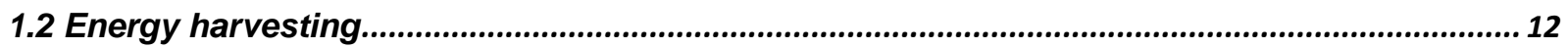

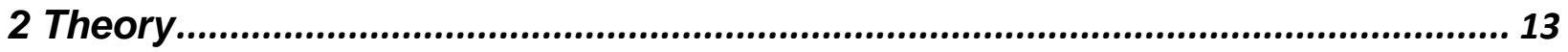

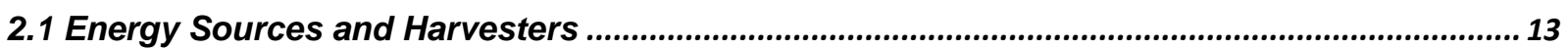

2.1.1 Solar as an Energy Harvesting Source and Solar Cells.......................................................13

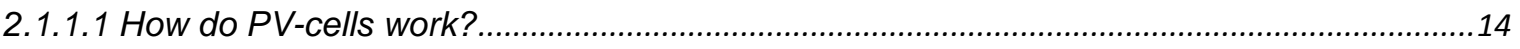

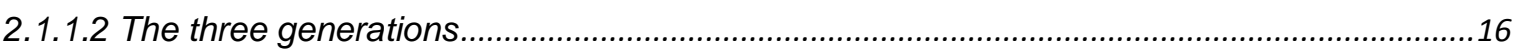

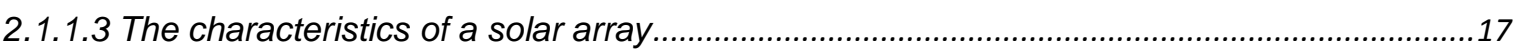

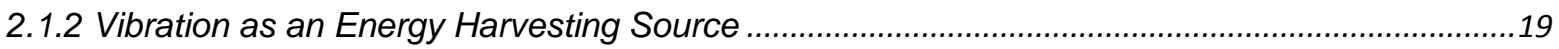

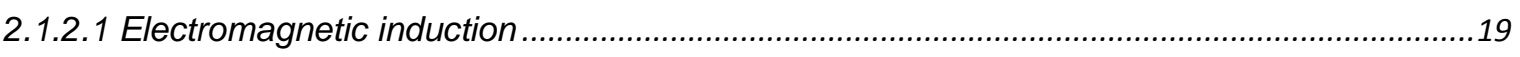

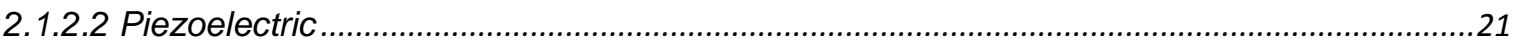

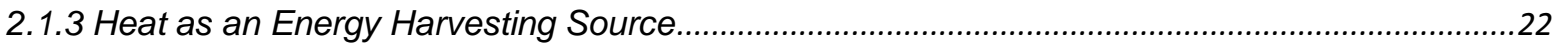

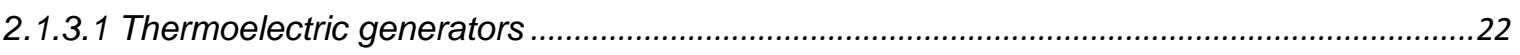

2.1.4 Radio Frequency (RF) as an Energy Harvesting Source..........................................................25

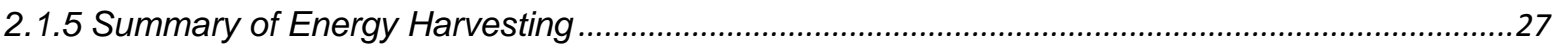

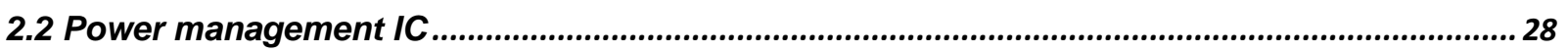

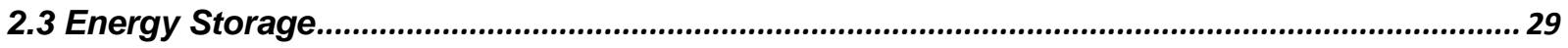

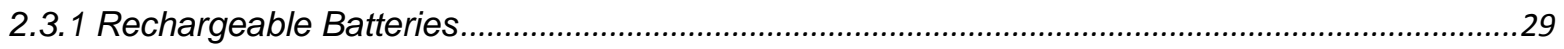

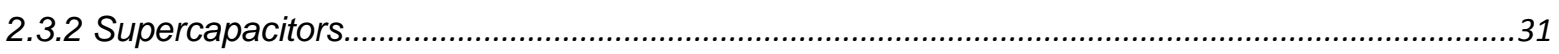

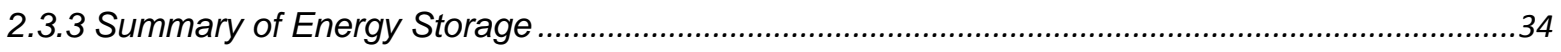

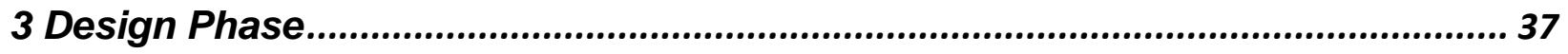

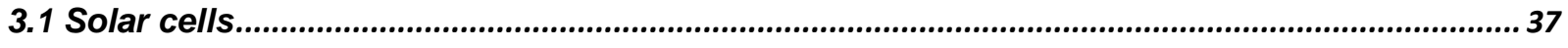

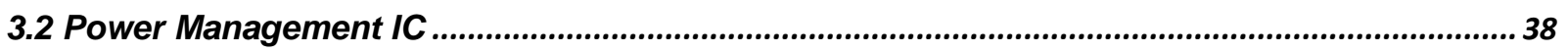

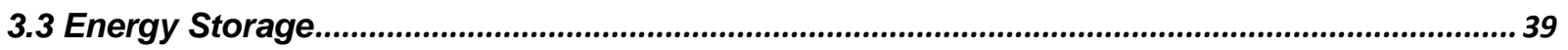

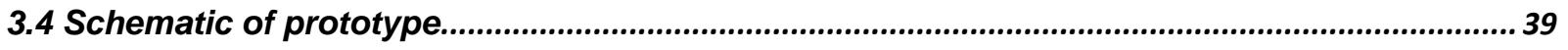

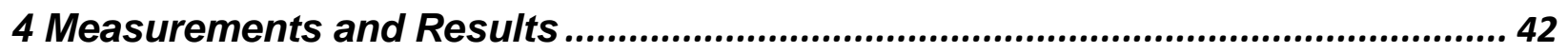

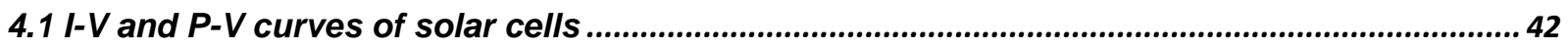

4.2 Charge- and discharging-time of the supercapacitor .......................................................... 49

4.3 Test with SMB .......................................................................................................................................... 52

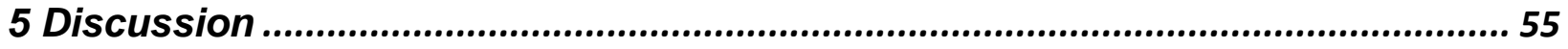

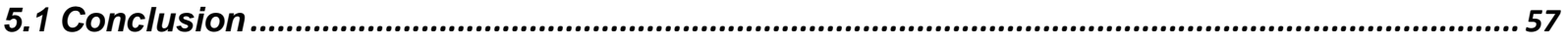

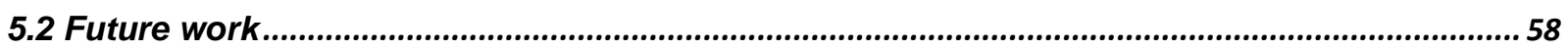

References ................................................................................................................ 59 
Appendices ................................................................................................ 62

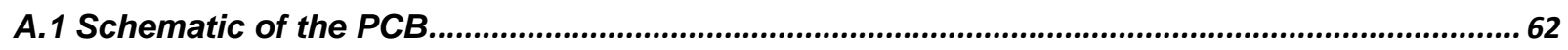

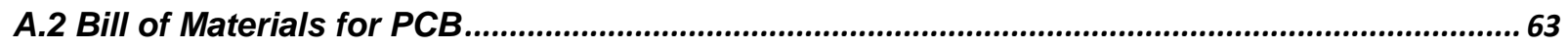




\section{List of Figures}

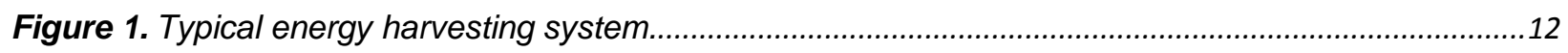

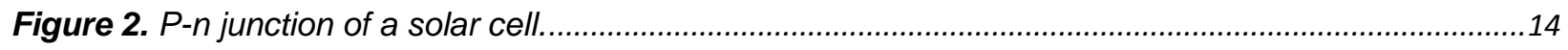

Figure 3. Spectra of a white LED, CFL and Incandescent bulb. The global standard spectrum, AM1.5G.

[4].

Figure 4. Absorption edge for dye-sensitized- (DSSC), amorphous silicon- (a-Si), galium arsenide(GaAs) and galium indium phosphide- (GalnP) solar cells. [5]

Figure 5. I-V and P-V characteristics of a solar cell. [9].

Figure 6. I-V characteristics for series and parallel connected solar cells. [9].

Figure 7. Typical piezoelectric cantilever. [14].

Figure 8. The left figure illustrates a thermoelectric generator, and the right figure illustrates a thermoelectric refrigerator. [13].

Figure 9. Occupied frequency band in Sweden a) is for outdoor b) is for indoor. ISM is the frequency band used in Industrial, Scientific and Medical. DECT is the band for cordless phones, its stands for Digital European Cordless Telecommunications. [17].

Figure 10. Fundamentals of wireless power transmission. [13] ..........................................................26

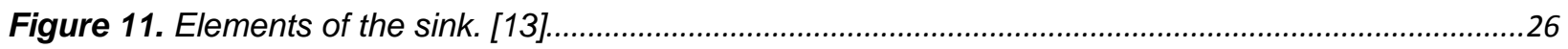

Figure 12. Output voltage during discharge from various rechargeable battery-technologies. [25]............31

Figure 13. Schematic of a conventional capacitor. [26] ..........................................................................31

Figure 14. Supercapacitor divided into three classes. [27]...................................................................33

Figure 15. Schematics of a typical double-layer capacitor. [26].................................................................33

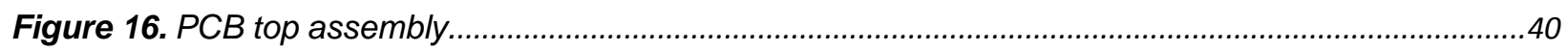

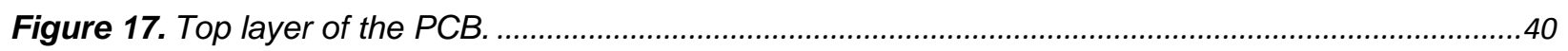

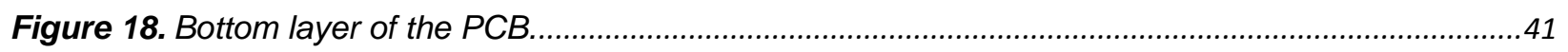

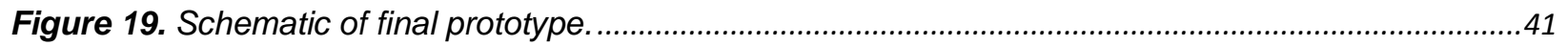


Figure 20. The test equipment. To the left the climate cabinet, with Lux meter sensor and solar cell. To the right a variable resistor, an ampere meter and a volt meter.

Figure 21. I-V measurement schematic.

Figure 22. I-V and P-V curves for solar cell from Alta Devices exposed to a light intensity of 600 Lux with an Incandescent bulb.

Figure 23. I-V and P-V curvse for solar cell from Alta Devices exposed to a light intensity of 600 Lux with a LED module. 44

Figure 24. I-V and P-V curves for solar cell from Panasonic exposed to a light intensity of 600 Lux with an Incandescent bulb.

Figure 25. I-V and P-V curves for solar cell from Panasonic exposed to a light intensity of 600 Lux with a LED module.

Figure 26. Power density as a function of light intensity exposed to LED illumination. .47

Figure 27. Power density as a function of light intensity exposed to Incandescent illumination. .47

Figure 28. Power density as a function of temperature exposed to LED illumination. .48

Figure 29. The setup when testing charge- and discharge-time with resistor as system load... .50

Figure 30. Charge-time for supercapacitor bank exposed to light intensity of 600 Lux and $1.73 \mathrm{~mW}$ of input power.

Figure 31. Discharge-time for supercapacitor bank with resistor as system load draining $1 \mathrm{~mW}$. .51

Figure 32. Test rack where tests on the SMB were done. .52

Figure 33. Charge-time for supercapacitor bank exposed to light intensity of 700 Lux. . .53

Figure 34. Discharge-time for supercapacitor bank with SMB as system load draining maximum $1 \mathrm{~mW} . .53$

Figure 35. IRC5 robot controller to determine if power supply to the SMB was lost during Battery mode. 54

Figure 36. Test with SMB during 3 weeks. 54

Figure 37. Schematic of the prototype. 62 


\section{List of Tables}

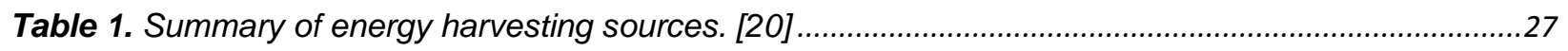

Table 2. The standard electrode potential for common battery technologies. [23] [24]..............................30

Table 3. Energy density for Li-lon, Ni-Cd and supercapacitor. [29] [30] ..................................................35

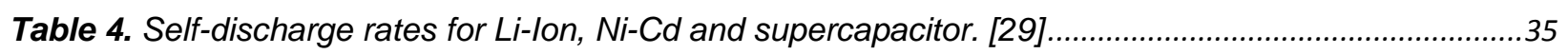

Table 5. Recharge time for Li-lon, Ni-Cd and supercapacitor............................................................36

Table 6. Life time for Li-Ion, Ni-Cd and supercapacitor. [31] ..............................................................36

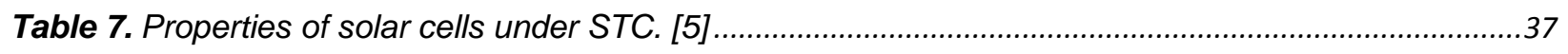

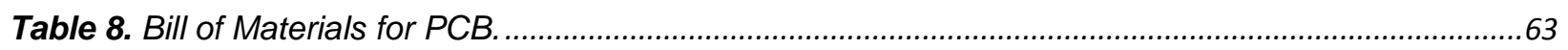




\section{Abbreviations}

$\begin{array}{ll}\text { SMB } & \text { Serial Measurement Board } \\ \text { EHS } & \text { Energy Harvesting System } \\ \text { EH } & \text { Energy Harvesting } \\ \text { RF } & \text { Radio Frequency } \\ \text { PMIC } & \text { Power Management Integrated Circuit } \\ \text { PV } & \text { Photovoltaic } \\ \text { CFL } & \text { Compact Fluorescent } \\ \text { a-Si } & \text { Amorphous-Silicon } \\ \text { GaAs } & \text { Gallium-Arsenide } \\ \text { STC } & \text { Standard Test Conditions } \\ \text { TEG } & \text { Thermoelectric Generators } \\ \text { MPPT } & \text { Maximum Power Point Tracking } \\ \text { PCB } & \text { Printed Circuit Board }\end{array}$




\section{Introduction}

\subsection{Background}

The use of sensors in industrial robots has increased rapidly in recent years. The disadvantages with sensors are that they use batteries for power supply, meaning that regular checks and replacement of batteries have to be done. This is both a costly and time-consuming work. An alternative to batteries can be Energy Harvesting (EH), which means that energy available in the environment is recovered and converted to power for a small electronic device, such as a sensor.

There is a significant difference between $\mathrm{EH}$ and energy mass production; the difference is that in the second one the generated power is in the kilowatts to gigawatts order, where the aim is to power cities, offices, factories, and so on. For EH the generated power is in the microwatts order, where the aim is to power small electronic devices such as sensors, microcontrollers and wireless transceivers.

\subsubsection{Serial Measurement Board (SMB)}

$A B B$ has a SMB mounted in their robots. The main objective of the SMB is to gather resolver data from the robot's motors, which in turn is used to measure the speed and position of each resolver. An ABB robot generally consists of 6-7 resolvers.

The SMB has three different operation modes:

- Normal mode

- Battery mode

- Transport mode

In Normal mode the power to the SMB is supplied by $24 \mathrm{~V} \mathrm{DC}$ voltage from the system power supply, meaning the robot is operating, while in Battery and Transport mode the robot is shut down and the power to the SMB has to come from an external power source.

When in Battery mode all resolvers are connected and the power consumption shall not exceed $1 \mathrm{~mW}$. While in Transport mode the power consumption shall not exceed 0.2 $\mathrm{mW}$. The input voltage range to the SMB can be between $3-12 \mathrm{~V}$. 


\subsubsection{Problem formulation and specification}

The objective with this thesis is to investigate the possibility of $\mathrm{EH}$ as the external power for the SMB. To do this the entire EH chain from an energy source via an energy harvester, and power manager to the energy storage has been investigated and from that a physical proof of concept has been developed and tested.

The minimum power generated by the physical prototype has to be $1 \mathrm{~mW}$ with an output voltage of 3-12 V and as energy storage element supercapacitors are highly desirable.

\subsubsection{Thesis outline}

The report is structured in four parts:

Chapter 2 includes necessary theory of energy sources, power management integrated circuit and energy storage.

Chapter 3 includes the design phase of a proof of concept circuit with the hardware and schematics of the circuit.

Chapter 4 consists of results from the measurements.

Chapter 5 presents discussions and summaries of the results from this thesis work. 


\subsection{Energy harvesting}

The idea of Energy Harvesting is to capture small amounts of energy that occur in the surrounding environment, that otherwise would be wasted as heat, light, sound, vibration or movement, and use this to power small electronic devices.

The advancements in circuit and semiconductor technology have made the power consumption of microelectronic circuits and processors decrease significantly. In parallel, the efficiency of energy transducers such as solar cells, thermoelectric, and inductive generators is increasing by means of material and system improvements.

By applying $\mathrm{EH}$ there is a potential to completely eliminate the use of batteries in such small electronic devices. This would be extremely applicable for example in large buildings, where thousands of sensors for monitoring temperature and humidity are spread out. Changing batteries in those sensors is costly as well as time-consuming. Another aspect where this technology would be appreciated is in tough environments like semi-active volcanoes, where sensors are placed to monitor geoseismic activity and send back data.

Typically, an Energy Harvesting System (EHS) consists of the following: an Energy Source, such as solar-, radio frequency-, kinetic- and thermal-energy, an Energy Harvester, for example a solar cell or a thermoelectric generator, a power management integrated circuit (PMIC) and an Energy Storage element, as depicted in Figure 1. In the next chapter, a deeper review of properties and functionalities of these will be made.

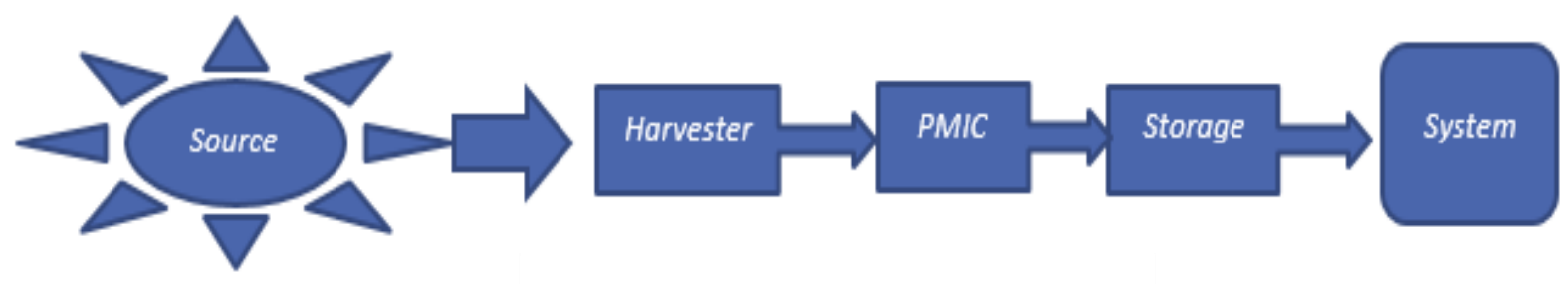

Figure 1. Typical energy harvesting system. 


\subsection{Energy Sources and Harvesters}

\subsubsection{Solar as an Energy Harvesting Source and Solar Cells}

Without a doubt one of the most important renewable energy sources is solar energy. That is because compared with other energy sources it has the greatest availability of them all, as well as being clean and free of emissions. The amount of solar radiation hitting the earth just for one minute would provide with enough energy to supply the world's energy needs for one year. [1]

The first use of sunlight as an energy source was to ignite fires. It was not until the end of eighteenth century, more specifically 1883 , the first working solar cells were invented by Charles Fritts. These solar cells were built of selenium, with an efficiency of about 1\%. 1954 researchers Calvin Fuller, Daryl Chapin, and Gerald Pearson, developed silicon solar cells with an efficiency of $6 \%$ [2]. During the 1950s the efficiency increased up to $10 \%$, but due to the high costs commercial applications were limited.

In May 2016 engineers at the University of New South Wales in Australia achieved a new world efficiency record of $34.5 \%$. They used a four-junction solar cell which was embedded with a prism to extract maximum energy from the sunlight. The prism splits the incoming rays into four bands, where each band hits a four-junction receiver to squeeze even more electricity from that band [3]. As usual with new techniques it will take some time before it is available for general use. For this technique the manufacturing process is complex and therefore the cost is more than those available in the market today.

A solar cell also called a photovoltaic (PV) cell, converts sunlight into electricity. This physical process is known as photoelectric effect. Today's solar cell technologies are divided into three main categories called generations. The majority of the first generation consists of crystalline silicon and the second of amorphous silicon. These are the leading solar cells on today's market. The third generation consists of organic materials such as small molecules or polymers. The world's most efficient solar cell described above is covered by this generation. More about these generations in the upcoming sections. 


\subsubsection{How do PV-cells work?}

Photovoltaic cells consist of at least two doped semiconductor layers. One layer contains a positive charge (holes) and the other a negative charge (electrons), which are bound together by a p/n-junction. When light shines on a PV-cell, the photons (which are small particles of energy that light consists of), are either reflected, pass through or absorbed by the PV-cell. The absorbed photons make the charges move to the respective junction, that is the holes move to the positive layer and the electrons move towards the negative layer, this is illustrated in Figure 2. The area in the middle is called the depletion area, which is produced by the movements of the charges. This results in a voltage difference between the layers. If a load is connected to a cell, the electrons move through the load generating an electric current. [2]

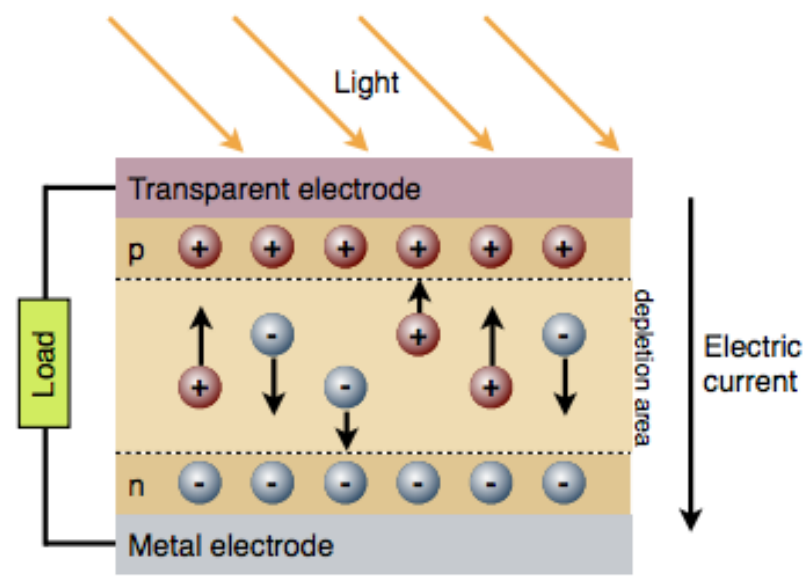

Figure 2. P-n junction of a solar cell.

The typical spectrum for outdoor extends from the UV to the Near Infrared, and the majority of the solar cells on the market are optimized for outdoor use. For indoor applications, where the light sources are typically artificial sources, such as LEDs, CFLs and Incandescent bulbs, the produced spectrum lies in the visible light region (400-700 $\mathrm{nm}$ ). It is important that indoor solar cells are manufactured with strong absorption in this range. Figure 3 shows the representative spectra of white LED, Compact Fluorescent (CFL), Incandescent bulbs and the global standard spectra. 


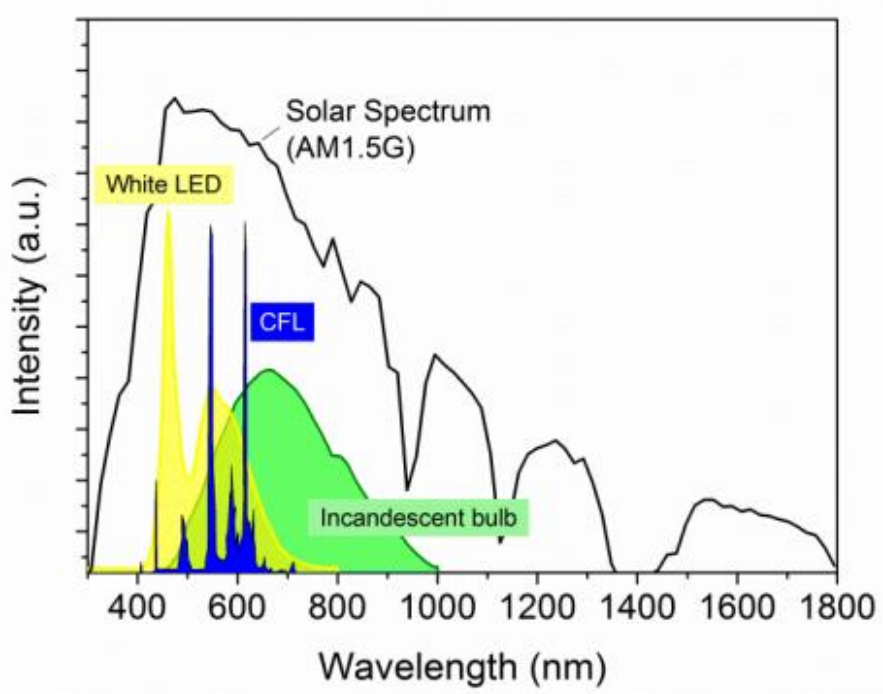

Figure 3. Spectra of a white LED, CFL and Incandescent bulb. The global standard spectrum, AM1.5G. [4]

More power can be harvested by solar cells if its spectral sensitivity fits the radiant spectra of the light, i.e. if a solar cell has a larger absorption edge more power can be harvested. As seen in Figure 4 the absorption edge that gallium arsenide (GaAs) solar cells have is the largest one compared to the other solar cells. As can be seen in Figure 3 the radiant spectra for Incandescent bulb is the largest of the artificial lightning. The result is that more power can be harvested with Incandescent lightning than with white LED or CFL.

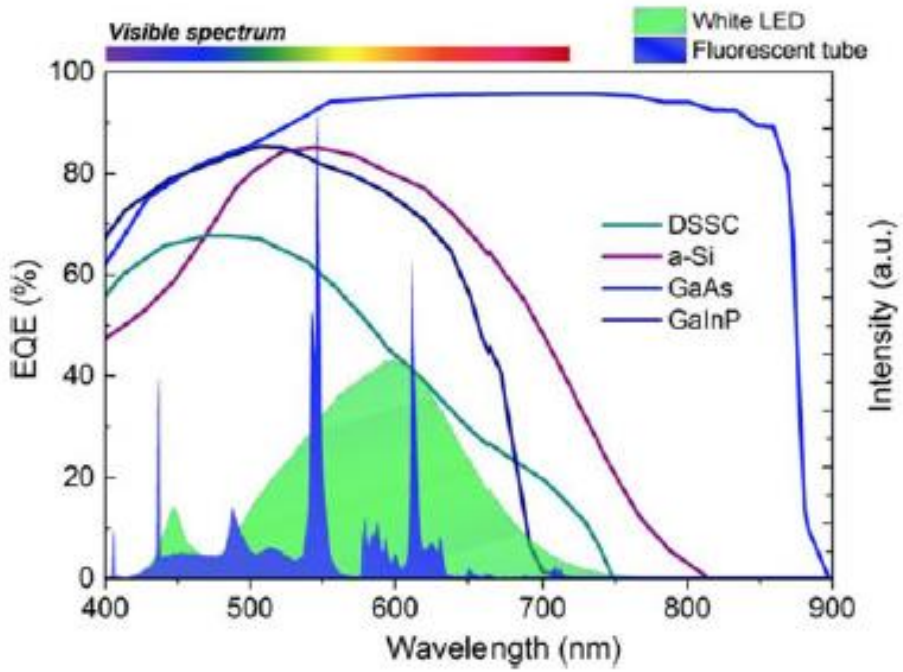

Figure 4. Absorption edge for dye-sensitized- (DSSC), amorphous silicon- (a-Si), galium arsenide- (GaAs) and galium indium phosphide- (GalnP) solar cells. [5] 


\subsubsection{The three generations}

\section{First generation}

As mentioned before the first generation consists of doped single crystalline silicon or germanium. In 1958 the first satellite was powered by crystalline solar cells. Today you can see them on rooftops and solar-farm systems around the world. They have a lifetime of 23-35 years and are capable of handling atmospheric components such as water very well. The production costs are relatively expensive, due to the pure silicon or germanium is needed. The highest reported efficiency for a crystalline cell is about 25.6 $\pm 0.5 \%$ [6]. All the tests for measuring efficiency on solar cells are done under standard test conditions (STC), which is under a radiation of $1000 \mathrm{~W} / \mathrm{m}^{2}$ at $25^{\circ} \mathrm{C}$ which correspond to a clear day. Some advantages with the first generation PV cells are the good performance and the lifetime. Some disadvantages are that they perform poor in low-light and, as outlined before, the high production costs. [7] [8]

\section{Second generation}

The second generation, also called thin-film solar cells, includes amorphous silicon (aSi), Copper Indium Gallium Selenide (CIGS) and Cadmium Telluride (CdTe). In 1976 the first solar powered calculator, the EL-8026 from Sharp, was powered by amorphous solar cells. As in the first generation you can see these solar cells on rooftops. They have a lifetime of 10-17 years, and the efficiencies under STC are $13.6 \pm 0.4 \%$ for a-Si, $18.7 \pm 0.6 \%$ for CIGS and $18.6 \pm 0.6 \%$ for CdTe [6]. The production costs are less than for the first generation. This is because the semiconductor material that the solar cells are made of is only a few micrometers thick. This is also the reason why they are called thin-film solar cells. Some advantages are that they are light-weight and easy to integrate and as mentioned above more cost friendly than the first generation solar cells. Disadvantages are the low efficiencies as well as toxicity concerns. CIGS and CdTe use cadmium, which is classified as one of the sixth most toxic substances. [7] [8]

\section{Third generation}

The third generation includes many different types of variations. They vary in material, material composition, synthesis, combination or the way they are built-up. Dyesensitized - (DSSC), quantum-dot - (QD) and multi-junction solar cells are some of those included in the third generation. Their lifetime is between 10-17 years. A lot of research is going on in these technologies, and they are for the most part not yet commercially available. Those that are, either cost too much or are not yet available on a large scale. Efficiencies under STC are $11.9 \pm 0.4 \%$ for DSSC and $28.8 \pm 0.9 \%$ for multi-junction built from gallium arsenide (GaAs). [6] [7] [8] 


\subsubsection{The characteristics of a solar array}

With the help of the parameters below, the electrical characteristics of a photovoltaic array can be summarized:

Open Circuit Voltage $\left(V_{o c}\right)$ : This is the maximum voltage that appears over the solar cell when no load is connected.

Short Circuit Current $\left(I_{s c}\right)$ : When short circuiting the terminals of a solar cell, the maximum current flows between them.

Maximum Power $\left(\boldsymbol{P}_{\max }\right)$ : This is the maximum power that a solar cell can generate, which change depending on the light intensity of the irradiation and temperature. To find the point where the output power is at its maximum, a maximum power point tracking (MPPT) system can be used. In theory the maximum power point can be found at $80 \%$ of the open circuit voltage.

Efficiency: The ratio of maximum power the array can generate and the amount of solar irradiance hitting the array.

Fill Factor (FF): The ratio of maximum power and the product of $V_{o c}$ and $I_{s c}$. By knowing this fill factor an idea of the quality of the array is given. The closer the fill factor is to 1 the more power the array generates. Typical values are between 0.7-0.8. In Figure 5 the area A represents FF.

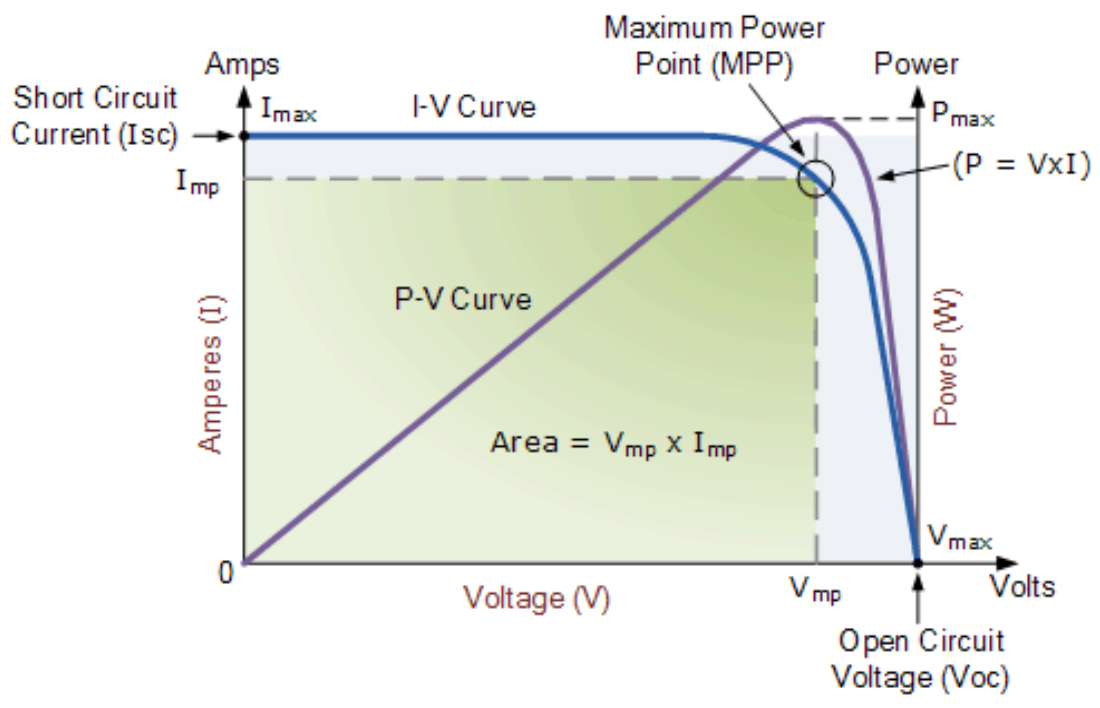

Figure 5. I-V and P-V characteristics of a solar cell. [9]

In Figure 5 above, a solar cell's I-V characteristics curve is shown, which provides the required information to configure a solar system to operate as near as possible to its maximum power point.

The current is changed with the intensity of the solar irradiation that hits the cell, while the voltage drops with an increase of temperature. Increasing the temperature results in 
a reduction of the band gap of a solar cell, which in turn affects the material parameters of the solar cell.

Solar panels change in characteristics if they are connected in either series or parallel combination. As seen in Figure 6 below, in parallel the current is increased, while in series the voltage is increased. The maximum power point will always be in the upper right hand corner. [9]

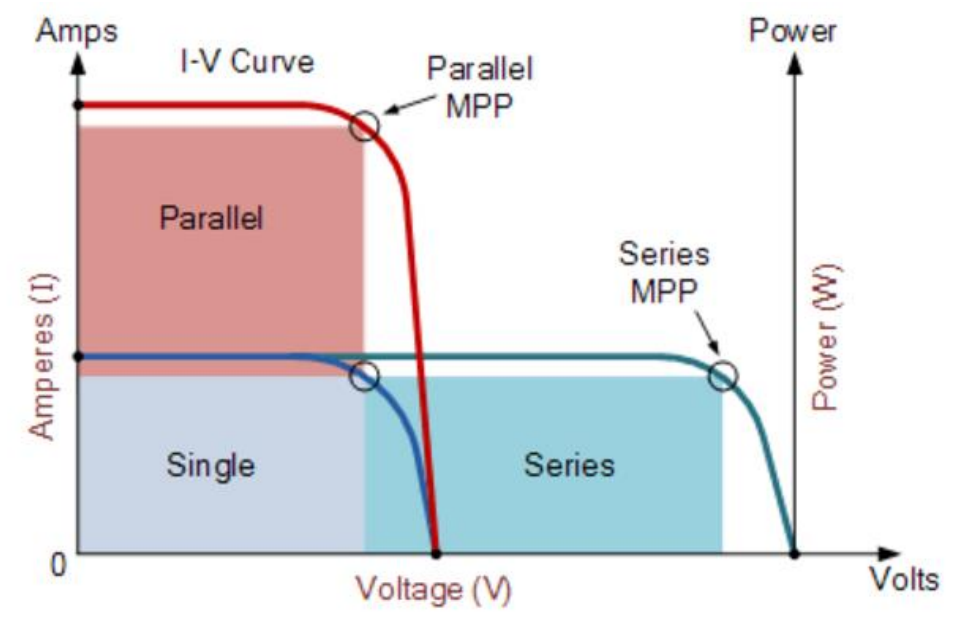

Figure 6. I-V characteristics for series and parallel connected solar cells. [9] 


\subsubsection{Vibration as an Energy Harvesting Source}

There are various methods for converting mechanical energy into electrical energy. These methods are mostly based on electromagnetic and piezoelectric materials. Due to the simplicity in the design and the ability to directly convert applied strain energy into electric energy, the piezoelectric material has an advantage over the electromagnetic material. [10]

\subsubsection{Electromagnetic induction}

This section is based on background data from [11].

Michael Faraday, James Maxwell, Joseph Henry and Heinrich Hertz were some of the nineteenth century scientists who worked with electromagnetism. For example, the relationship between magnetic and electric fields is described by Maxwell's equations. Maxwell's third equation, Faraday's law of induction, describes that an electric field is induced by a time varying magnetic field.

The first electromagnetic generator was developed by Michael Faraday. He discovered that a potential difference (i.e. a voltage) is induced across the terminals of an electrical conductor when this is moved through a magnetic field. The electrical conductor is a coil of wire of multiple turns and the magnetic field is created by permanent magnets. The induced voltage in a coil of $N$ turns is given by:

$$
V=-N \frac{d \phi}{d t}
$$

where $V$ is the generated voltage [V] and $\phi$ is the flux linkage [Wb-t]. Assuming that the motion between the coil and the magnet is in the $x$-direction, the voltage is then expressed as:

$$
V=-\frac{d \phi}{d x} \frac{d x}{d t}=-N \frac{d \phi}{d t} \frac{d x}{d t}
$$

By connecting a load resistance to the coil terminals power can be extracted. When doing this a current flows through the coil and creates its own magnetic field, which acts against the field giving rise to it. This generates an electromagnetic force, $F_{e m}$, which opposes the motion of the permanent magnet. Mechanical energy is transformed into electrical energy, by acting against this electromagnetic force. The electromagnetic force is expressed as the product of the velocity and an electromagnetic damping, $D_{e m}$, as

$$
F_{e m}=D_{e m} \frac{d x}{d t}
$$


When designing a generator, it is important to maximize the electromagnetic damping in order to generate maximum power.

By taking the product of the electromagnetic force and the velocity, the power, $P_{e}$, extracted by the force is given. This is shown in Equation (4) below.

$$
P_{e}=F_{e m} \frac{d x}{d t}
$$

The power dissipating to the load and coil is given by:

$$
P_{\text {diss }}=\frac{V^{2}}{R_{L}+R_{c}+j \omega L_{c}}
$$

where $R_{L}[\Omega]$ is the load resistance, $R_{c}[\Omega]$ is the coil resistance, and $L_{c}[\mathrm{H}]$ is the coil inductance.

By setting the power, $P_{e}$, equal to the power $P_{\text {diss }}$, and applying Equations (2) and (3), the electromagnetic damping can be written as:

$$
D_{e m}=\frac{1}{R_{L}+R_{c}+j \omega L_{c}}\left(\frac{d \phi}{d x}\right)^{2}
$$

As mentioned above, to generate maximum power the electromagnetic damping should be maximized. As seen in Equation (6), this can be done by minimizing the coil impedances and maximizing the flux linkage gradient, which depends on the magnets used, the area of the coil and number of turns in the coil. 


\subsubsection{Piezoelectric}

In 1880, the French brothers Curie discovered piezoelectric effect. They discovered that when crystals, such as quartz, topaz and Rochelle salt, were subjected to mechanical strain the crystals became electrically polarized. Piezoelectric material works also in reverse, i.e. by applying an electrical field it will generate a strain. The first practical use of piezoelectric effect was during World War 1, when developing an ultrasonic submarine detector. The basis was to use two steel plates with thin crystals of quartz glued between, and when applying a voltage, a high frequency of $50 \mathrm{MHz}$ was emitted underwater.

Today the piezoelectric effect is used in many application, such as electronic clocks, gas ovens, microscopes, and many more. [12] [13]

As mentioned above piezoelectric material utilizes direct piezoelectric effect. To maximize the energy harvesting performance the coupling between the piezoelectric material and the mechanical source is of importance. The more a piezoelectric material can withstand an applied force and recover from it, the higher the energy harvesting performance.

When choosing the piezoelectric material, the transduction rate is important. This rate changes with the product of the piezoelectric strain constant, $d$, and the effective piezoelectric voltage constant, $g$. Equation (7) shows that the generated electrical energy is higher if a material has a higher $(d * g)$ product:

where

$$
P=\frac{1}{2}(d * g) *\left(\frac{F}{A}\right)^{2} *(A t)
$$

$F$, is the applied force $[\mathrm{N}]$

$A$, is the area $\left[\mathrm{cm}^{2}\right]$

$t$, is thickness of the piezoelectric material [m].

Figure 7 shows a schematic of a typical piezoelectric cantilever, where one end is attached to the vibrating source and the other end has a tip mass attached to it. This will make the cantilever bend, which will result in energy generation. [14]

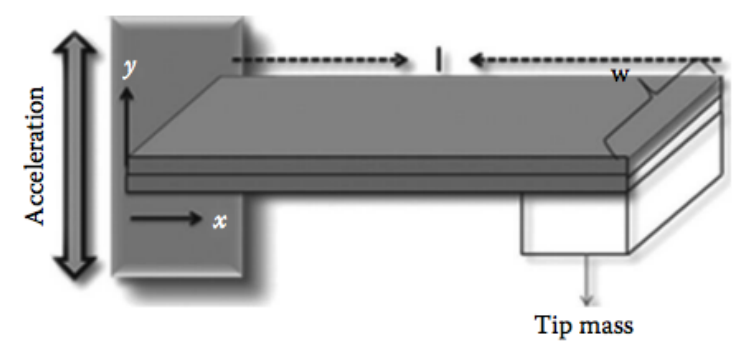

Figure 7. Typical piezoelectric cantilever. [14] 


\subsubsection{Heat as an Energy Harvesting Source}

Surroundings with heat flow and temperature differences have the potential to generate electrical power. This was discovered by Thomas J. Seebeck in 1821. He observed that two metallic conductors connected to one another, with different temperatures, deflected a compass needle when approaching it to the two metallic conductors. This deflection was due to an electric field which was created by the temperature differences between the conductors. Jean C. A. Peltier showed in 1834 that this effect also works in the opposite direction, i.e. if applying electricity to the two conductors a small heating or cooling effect is produced.

One type of heat converting generator that have gained more attention for energy harvesting application is thermoelectric generators. [13]

\subsubsection{Thermoelectric generators}

The simplest thermoelectric generators (TEG) are built from thermocouples, which are connected in series. A thermocouple is fabricated from $n$ - and $p$-doped semiconductors as shown in Figure 8.
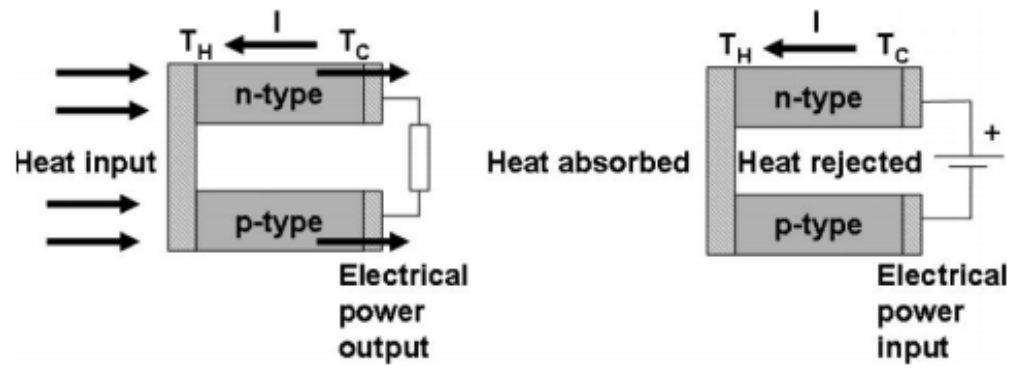

Figure 8. The left figure illustrates a thermoelectric generator, and the right figure illustrates a thermoelectric refrigerator. [13]

The two branches are joined to conductors with small electrical resistance. When heating up the materials, the charge carrier diffusion in the material at the hot side increases more than at the cold side. At the cold side of the $n$-doped material a collection of negative charges will appear, whereas at the cold side of the $p$-doped material a collection of positive charges will appear. This results in a potential difference between the cold sides of the semiconductors. This is called Seebeck effect, and by connecting a resistive load as can be seen in the left side of Figure 8 , the generated electric power can be used by the load. The right part of Figure 8 shows the Peltier effect, i.e. the resistive load is replaced by a current source. The thermocouple acts as a heat pump. [13] 
The power, $P$, and electrical current, $I$, delivered to the external load, $R$, in a TEG is denoted as:

$$
P=I^{2} R
$$

and

$$
I=\frac{S * \Delta T}{r+R}
$$

where $S$ is the thermopower $[\mathrm{V} / \mathrm{K}], r$ is the total internal electrical resistance of a thermoelement $[\Omega]$ and $\Delta T$ is the temperature difference $[\mathrm{K}]$. By inserting Equation (9) into Equation (8) we get:

$$
P=\frac{S^{2} \Delta T^{2} R}{(r+R)^{2}}
$$

The internal electrical resistance is denoted as:

$$
r=\frac{\alpha l}{\sigma A}
$$

where $\alpha$ stands for the number of thermoelements, $l$ is the length of the thermoelement $[\mathrm{m}], \sigma$ is the electrical conductivity [S/m], and $A$ is the cross-section area [ $\left.\mathrm{cm}^{2}\right]$.

To get maximum power $R$ should be equal to $r$, and by substituting this into Equation (10) and using the definition of the internal resistance $r$ the equation for maximum power is obtained:

$$
P_{\text {max }}=\Delta T^{2} * \frac{\alpha A}{4 l} * \sigma S^{2}
$$

When designing a TEG this equation can be used as a roadmap. As seen in the equation the first term shows that the temperature differences within the thermoelements play a role. The second term shows that the structure is of importance. The power generation can be increased by either increasing the total area or by decreasing the element thickness. The third term has to do with the type of material that is used. Doped Bismuth Telluride $\left(B i_{2} T e_{3}\right)$, is a material that commercially available TEGs are built up of. This is due to its good performance at room temperature.

The conversion efficiency in a TEG from heat into electric power is defined by:

$$
\eta=\frac{\text { energy available at } R_{L}}{\text { heat energy absorbed at hot junction }}
$$


The heat energy absorbed at the hot junction is given by:

$$
Q_{h}=\kappa \Delta T+S T_{h} I-\frac{I^{2} r}{2}
$$

where $\kappa$ is the thermal conductance $[W /(m * K)]$.

By using Equations (8) and (9) and defining $m=R / r$, the efficiency is expressed as:

$$
\eta=\frac{W}{Q_{h}}=\frac{\Delta T}{T_{h}} * \frac{\frac{m}{m+1}}{1+\frac{\kappa r(m+1)}{S^{2} T_{h}}-\frac{\Delta T}{2 T_{h(m+1)}}}
$$

Defining a figure of merit as:

$$
Z=\frac{s^{2} \sigma}{\lambda}
$$

This figure of merit assumes that the electrical conductivity, $\sigma$ thermal conductivity, $\lambda$, and the thermopower, $S$, are all constant over the temperature range of interest. It is common to expand this figure of merit to $Z T$, where $T=\left(T_{h}+T_{c}\right) / 2$. This is possible since all parameters are temperature dependent. $T_{h}$ is the temperature of the hot side and $T_{c}$ is the temperature of the cold side.

By inserting Equation (16) into (15):

$$
\eta=\frac{W}{Q_{h}}=\frac{\Delta T}{T_{h}} * \frac{\frac{m}{m+1}}{1+\frac{(m+1)}{Z T_{h}}-\frac{\Delta T}{2 T_{h(m+1)}}}
$$

In Equation (10), by choosing $R=r$, the maximum power output was achieved. To achieve the maximum efficiency, $R$ should be equal to $r m$, which is equal to $\sqrt{1+Z T}$. By inserting this into Equation (10), a TEG's maximum efficiency is:

$$
\eta_{\max }=\frac{\Delta T}{T_{h}} * \frac{\sqrt{1+Z T}-1}{\sqrt{1+Z T}+\frac{T_{c}}{T_{h}}}
$$

This equation shows that maximum efficiency is dependent on the temperature difference $\Delta T$ and $Z$ [15]. Like all heat engines, and as well TEGs, the efficiency cannot be greater than that of a Carnot cycle, which is represented by the first term. [16] 


\subsubsection{Radio Frequency (RF) as an Energy Harvesting Source}

After the early 1990s the wireless energy harvesting technology has been of interest. This due to the increased usage of modern technologies, such as TV, radio, mobile phones, satellite and Wi-Fi. Today one of the main goals that mobile device manufactures try to achieve is to eliminate any cables that powers devices, such as cell phones or laptops, and are therefore the research leaders in wireless power transmission. As seen in Figure 9 below, wireless networks, e.g. Bluetooth, WLAN, send out signals in the frequency band of about $2.4 \mathrm{GHz}$. These frequencies can be collected by an antenna, which are then converted to DC power using a rectifier. Antennas are explained more below.

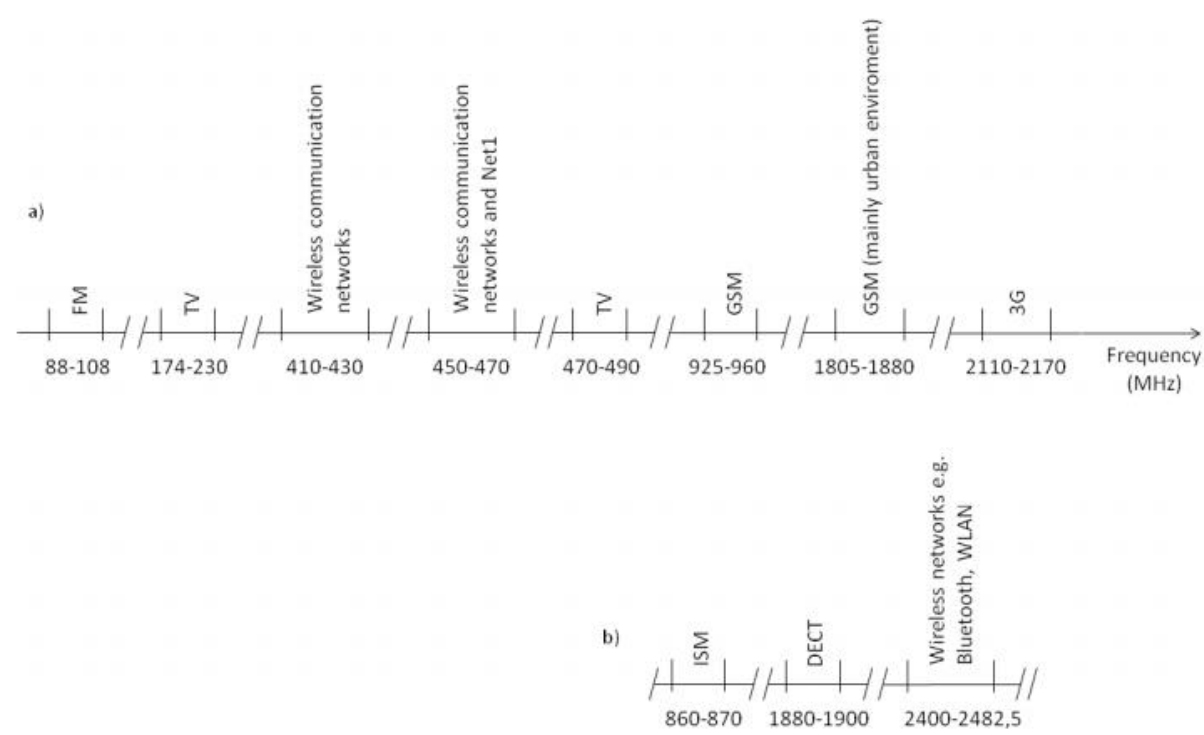

Figure 9. Occupied frequency band in Sweden a) is for outdoor b) is for indoor. ISM is the frequency band used in Industrial, Scientific and Medical. DECT is the band for cordless phones, its stands for Digital European Cordless Telecommunications. [17]

\section{Antennas}

The IEEE Standard Definitions of Terms for Antennas (IEEE Std 145-1983) describes the term "antenna" as: "That part of a transmitting or receiving system which is designed to radiate or to receive electromagnetic waves".

A wireless power transmission system has, as seen in Figure 10, two basic elements: a source that generates an electromagnetic field and a sink, which converts the receiving electromagnetic field to DC power. The medium, which the electromagnetic wave passes through, is called the transmission channel. It is normally air, but there can be solid materials in the way for the transmitting signal to reach the receiving antenna. 


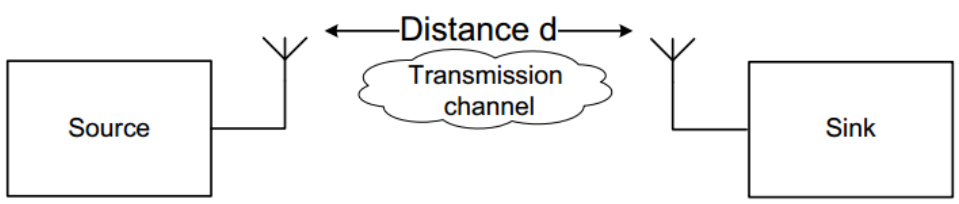

Figure 10. Fundamentals of wireless power transmission. [13]

The sink consists of an antenna, matching circuit, rectifier and a voltage converter, as depicted in Figure 11. The sink has influence on the efficiency of the whole circuit. To be more specific the shape and size of the antenna as well as the impedance matching between the antenna and the rectifier are of importance. A combination of an antenna and a rectifier is called rectenna. [13]

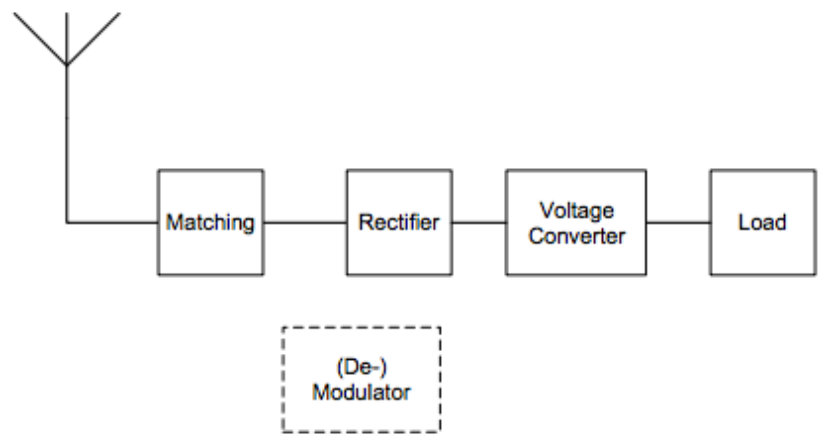

Figure 11. Elements of the sink. [13]

The power available at the output terminals of the receiving antenna, $P_{r}$, is given by Equation (19):

$$
P_{r}=\frac{A_{r} A_{t}}{d^{2} \lambda^{2}} * P_{t}
$$

where $P_{t}$ is the power at the input terminals of the transmitting antenna $[\mathrm{N}], \lambda$ is the wavelength [nm], $A_{r}$ and $A_{t}$ are the effective areas of the receiving respectively the transmitting antenna $\left[\mathrm{cm}^{2}\right]$ and $d$ is the distance between the antennas [m]. This equation is only valid for free space transmission, which means that there are no solid materials in between the transmitting and receiving antenna. If there were, the receiving power would decrease significantly. [18] 


\subsubsection{Summary of Energy Harvesting}

Due to the specification of this thesis some of the harvesting methods may be excluded for use. As the specifications say that the operating mode for the harvesting method is when the robot is shut down, vibration and heat as $\mathrm{EH}$ sources can be neglected in this thesis. RF energy harvesting is promising, as [19] show in their recent work that by optimizing the rectennas, this method is capable of competing with EH methods like PVcells and thermal elements in the future. In their work they also show that by connecting rectennas via a separate power manager to the same system, there is a possibility to extract energy simultaneously from different frequency bands. But the method is still on a research level. Also the amount of energy that can be harvested is very location dependent and hard to predict.

The only harvesting method that is left and which is used in this thesis is solar energy harvesting. But as the energy source withdraws during the night, the ability of buffering the energy is essential. Problems with solar cells are low absorption- and high reflection rate and the recombination of electrons and holes inside the solar cells, which leads to low efficiency. To increase the absorption rate different types of materials can be combined while for lowering the reflection rate antireflection coating can be applied on the solar cell surface or optics can be used to focus the incoming light. Table 1 gives a summary of the different energy harvesting sources.

Table 1. Summary of energy harvesting sources. [20]

\begin{tabular}{|c|c|c|c|c|c|}
\hline Harvester & Condition & $\begin{array}{c}\text { Power } \\
\text { Density } \\
(\mathbf{m W /} \\
\left.\mathbf{c m}^{2}\right)\end{array}$ & $\begin{array}{c}\text { Efficiencies } \\
(\%)\end{array}$ & Pros & Cons \\
\hline Solar & Outdoor & 100 & Up to $\sim 30$ & $\begin{array}{c}\text { Unlimited } \\
\text { during light }\end{array}$ & $\begin{array}{c}\text { Irregular } \\
\text { supply }\end{array}$ \\
\hline Solar & Indoor & 0.01 & Up to $\sim 30$ & $\begin{array}{c}\text { Unlimited } \\
\text { during light }\end{array}$ & $\begin{array}{c}\text { Irregular } \\
\text { supply }\end{array}$ \\
\hline Vibration & $1 \mathrm{~m} / \mathrm{s}^{2}$ & 0.06 & Up to $\sim 70$ & $\begin{array}{c}\text { Robustness, } \\
\text { high output } \\
\text { voltage }\end{array}$ & $\begin{array}{c}\text { Dependent on } \\
\text { some kind of } \\
\text { strain }\end{array}$ \\
\hline Thermal & Near a & $<0.001$ & Up to 70 & $\begin{array}{c}\text { Constant } \\
\text { power if } \\
\text { placed } \\
\text { strategically }\end{array}$ & $\begin{array}{c}\text { If not placed } \\
\text { strategically, } \\
\text { low power } \\
\text { density }\end{array}$ \\
\hline transmitter & $\Delta T=5{ }^{\circ} \mathrm{C}$ & 0.1 & $\begin{array}{c}\text { Constant } \\
\text { power if } \\
\text { placed } \\
\text { Carnot } \\
\text { efficiency with } \\
\text { ZT }=1\end{array}$ & $\begin{array}{c}\text { Dependent on } \\
\text { temperature } \\
\text { gradient to be } \\
\text { high }\end{array}$ \\
\hline
\end{tabular}




\subsection{Power management IC}

The Power Management Integrated Circuit, PMIC, is a part of the Energy Harvesting System, which converts an unstable, noisy, alternating input current, into a regulated direct current (DC current) and transfers it to the electronic device (the load system or the energy storage).

Due to the low power that is generated by the harvester, the main critical constraints when designing a PMIC are: high efficiency, low-power consumption, low-cost process integration and minimum chip area.

Generated voltages from the harvester are usually random, which at some point may be too low for the system to run at all and other times the input voltage may be higher than demanded. In case of solar energy harvesting, the voltage that is generated by a solar cell depends of the number of solar cells and the luminance level. To provide a constant input voltage into the load system or energy storage device, a DC-DC converter is necessary. The topology used in this thesis is the switching regulator, which is divided into two categories: buck converter and boost converter.

The output voltage is higher than the input in a boost converter, and vice versa in a buck converter. The boost converter is a step-up DC-DC converter and the buck converter is a step-down DC-DC converter. For the two converters the power balance is always valid, i.e. the power formula $P=V * I$ is always valid. If the output voltage is bigger than the input voltage (boost) then at the same time the output current is lower than the input current, resulting into a power balance between the input and the output.

Switching regulators have an efficiency as high as $80 \%-95 \%$. During conversion some power is lost due to internal resistance of components and the switching circuit.

One feature that PMICs should have when connected to a storage device is the ability to protect the storage device from being completely discharged and to avoid excessive charging voltage. This can be done by implementing charging thresholds, i.e. an overvoltage threshold to prevent overcharging and an under-voltage threshold to prevent depleting the storage device. By implementing these thresholds, damaging the storage device is avoided.

The implementation of this feature is quite hard, because there are different voltages and properties for various storage types. But one way to overcome this problem is by implementing ICs with programmable charging thresholds.

Another characteristic that is of importance is the maximum power point tracking (MPPT), which assures that the maximum power from a harvester is being transferred to the input of the PMIC. There are many algorithms to track the maximum power point. The algorithm used in this thesis is called The Open Circuit method, which operates by disconnecting the load from the source and measures the open circuit voltage, $V_{o c}$, 
generated by the harvester. This is repeated periodically. The maximum power output voltage, $V_{M P}$, is given by:

$$
V_{M P}=k * V_{o c}
$$

The $k$ value is a constant of proportionality and is typically between 0.7 and 0.8 [21]. As seen in Figure 5, at the maximum power output voltage the maximum power lies $P_{\max }$.

\subsection{Energy Storage}

Energy storage is essential when designing an energy harvesting system. That is because there will be situations when there is insufficient ambient energy to harvest. For example, if a system is only relying on solar cells then at night this system will stop working. This problem is solved by storing harvested energy that can be used when there is no energy to scavenge from the environment. An ideal storage element is one that is not bulky even though storing high amounts of energy, has no leakage discharge, loses no capacity for an infinite number of charge-discharge cycles, and has no geographic restrictions.

There are several types of storage elements, such as batteries and capacitors. Batteries are divided into two main groups: primary batteries and secondary batteries. Primary batteries are used once and then discarded, while secondary batteries, even called rechargeable batteries, as implied by their name are rechargeable and can be reused. An evolution of capacitors is the supercapacitor, which can store higher amount of energy than capacitors.

In the following section the function, advantages and disadvantages of supercapacitors and rechargeable batteries are discussed. [13]

\subsubsection{Rechargeable Batteries}

Rechargeable batteries store energy in a construction called an electrochemical cell, which consists of essentially three components: a negative electrode, called anode, a positive electrode, called cathode, and a chemical called electrolyte in between them. The ions in the electrolyte chemical react with the atoms in the anode, resulting in a build-up of electrons in the anode. These unbalanced electrons cause the anode to be negative. In the cathode, the chemical reaction with ions from the electrolyte causes a lack of electrons, making it positive. To prevent the electrons to flow directly from the anode to the cathode within the battery, the electrolyte acts as a barrier. The only way the electrons in the anode can flow to the cathode is if the circuit is closed, i.e. both ends of a battery are connected by for example a wire. This is called an oxidationreduction (redox) reaction. The loss of electrons in the anode is called oxidation, while the gain of electrons in the cathode is called reduction. The ability of these reactions determines the voltage that a cell generates. This is called Standard Electrode potential 
$\left(E^{0}\right)$, which is given in Volts, and is stated as reduction reaction with reference to a hydrogen electrode. The theoretical voltage of a cell is given by: [22]

$$
E_{\text {cell }}^{0}=E_{\text {cathode }}^{0}-E_{\text {anode }}^{0}
$$

Table 2 lists some standard electrode potential for common battery technologies.

The hydrogen was arbitrarily defined as zero potential, and thus is the reference for the other reactions. These reactions are given during charging, but are also reversible during discharge, and the equations will flow from right to left instead.

Table 2. The standard electrode potential for common battery technologies. [23] [24]

\begin{tabular}{|c|c|c|}
\hline $\begin{array}{c}\text { Battery } \\
\text { technology }\end{array}$ & Reactions (Reduction reaction) & $E^{0}(\mathrm{~V})$ \\
\hline $\mathrm{Li}$ & $L i^{+}+e^{-} \rightarrow L i(s)$ & -3.05 \\
\hline $\mathrm{Ni}-\mathrm{Cd}$ (cathode) & $2 \mathrm{NiOOH}+2 \mathrm{H}_{2} \mathrm{O}+2 e^{-} \rightarrow 2 \mathrm{Ni}(\mathrm{OH})_{2}+2 \mathrm{OH}^{-}$ & +0.48 \\
\hline $\mathrm{Ni}-\mathrm{Cd}$ (anode) & $\mathrm{Cd}(\mathrm{OH})_{2}+2 e^{-} \rightarrow \mathrm{Cd}+2 \mathrm{OH}^{-}$ & -0.82 \\
\hline $\mathrm{H}$ & $2 H^{+}+2 e^{-} \rightarrow H_{2}$ & 0 \\
\hline $\begin{array}{l}\text { Lead-Acid } \\
\text { (cathode) }\end{array}$ & $\mathrm{PbO}_{2}+\mathrm{SO}_{4}^{2-}+4 \mathrm{H}^{+}+2 e^{-} \rightarrow \mathrm{PbSO}_{4}+\mathrm{H}_{2} \mathrm{O}$ & +1.70 \\
\hline $\begin{array}{l}\text { Lead-Acid } \\
\text { (anode) }\end{array}$ & $\mathrm{PbSO}_{4}+2 e^{-} \rightarrow \mathrm{Pb}+\mathrm{SO}_{4}^{2-}$ & -0.35 \\
\hline
\end{tabular}

Lead-Acid, Nickel-Cadmium, Nickel-Metal-Hydride, Lithium-lon, Lithium-Polymer and Lithium-Iron-Phosphate, are some of the topologies for making rechargeable batteries.

Figure 12 shows the output voltage from various rechargeable battery-technologies during discharge. As seen in the figure, the most distinctive is the beginning and the end of the curves, i.e. when the battery is first connected and when the battery is nearly discharged. While in the middle the different technologies show an almost constant output voltage, which is a highly desirable property of batteries. [25] 


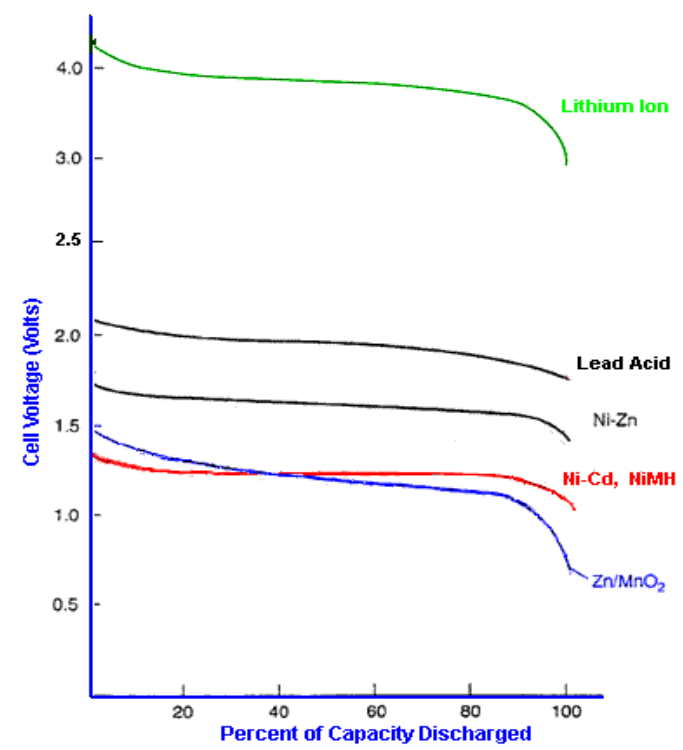

Figure 12. Output voltage during discharge from various rechargeable battery-technologies. [25]

\subsubsection{Supercapacitors}

The content in this section is based on information from [26].

A capacitor consists of two conductive electrodes separated by a dielectric (i.e. insulator), meaning that no current will flow through the material when voltage is applied. The dielectric separates the charges, thus producing an electric field that allows the capacitor to store energy. On the surfaces of each electrode, charges are accumulated when a voltage is applied to a capacitor. This can be seen in Figure 13.

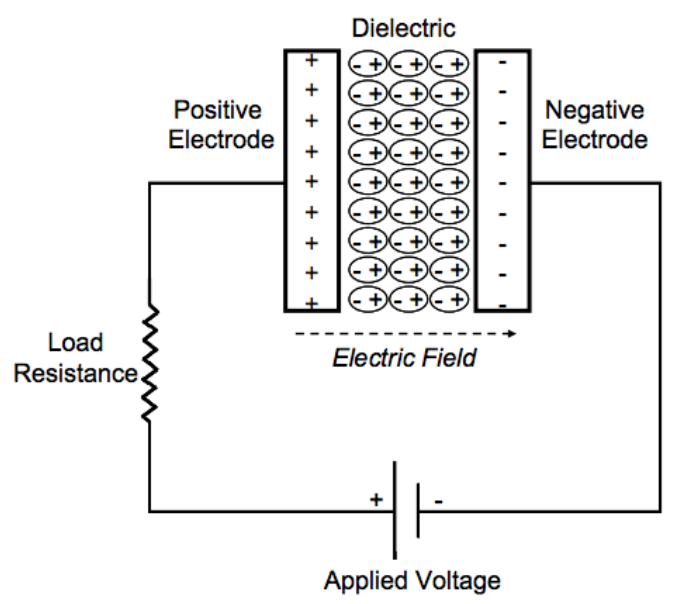

Figure 13. Schematic of a conventional capacitor. [26] 
Capacitance, $C$, is expressed as the ratio of stored (positive) charge, $Q$, with respect to applied voltage $V$ :

$$
C=\frac{Q}{V}
$$

The capacity is given in Farads, $F$, and the stored charges, $Q$, in Coulombs.

For a conventional capacitor, the capacitance is proportional to the area, $A$, of each electrode and inversely proportional to the distance between the electrodes, $D$ :

$$
C=\varepsilon_{0} \varepsilon_{r} * \frac{A}{D}
$$

where $\varepsilon_{0}$, is the dielectric constant of free space $[\mathrm{F} / \mathrm{m}]$, also called the permittivity and $\varepsilon_{r}$ is the dielectric constant of the insulting material between the electrodes $[\mathrm{F} / \mathrm{m}]$.

By integrating the amount of charges stored for a given voltage, the energy, $E$, stored in a capacitor is derived. This is given by Equation (24):

$$
E=\int_{0}^{Q} V d q=\int_{0}^{Q} \frac{q}{C} d q=\left[\frac{1}{2} \frac{q^{2}}{C}\right]_{0}^{Q}=\frac{1}{2} C V^{2}
$$

When determining the maximum power, $P_{\max }$, capacitors are generally represented, as depicted in Figure 13, with an external resistor, $R$, in series. This resistance consists of ohmic conduction and dielectric reversal losses and is known as equivalent series resistance (ESR).

$$
P_{\text {max }}=\frac{V^{2}}{4 * E S R}
$$

As seen from Equation (25) the maximum power of a capacitor can be limited by ESR. The maximum energy, $E$, is given in $W s$ and the maximum power, $P$, in $W$.

The basic principles of a capacitor are the same in a supercapacitor. But with the difference that the surface areas $A$ of the electrodes are much higher and the dielectrics are much thinner, which decreases the distance, $D$, between the electrodes. With these changes the capacity and energy storage for supercapacitors are higher than in a conventional capacitor. This can be seen from Equations (23) and (24).

Supercapacitors can be divided into three general classes: electrochemical double-layer capacitors, pseudo-capacitors and hybrid capacitors, as seen in Figure 14. 


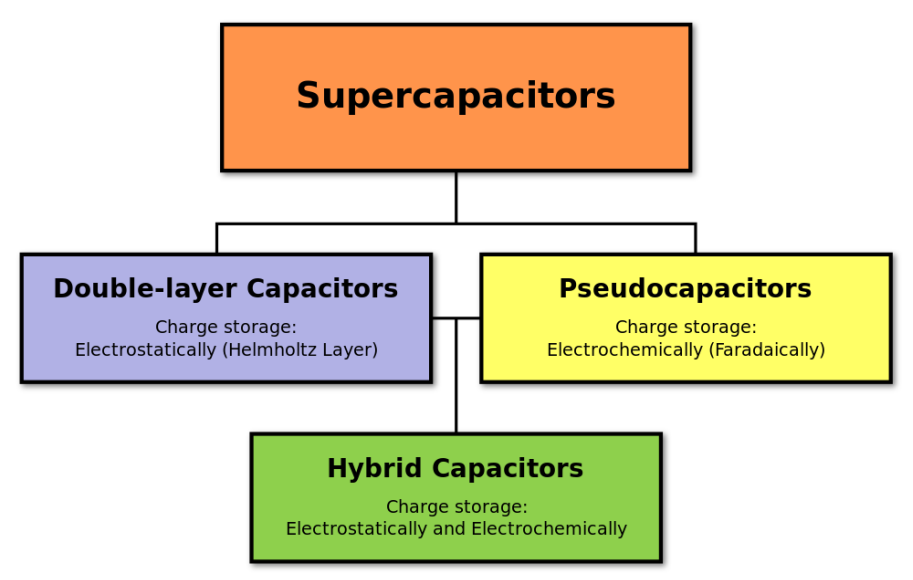

Figure 14. Supercapacitor divided into three classes. [27]

Double-layer capacitors consist of two electrodes based of carbon, an electrolyte and a separator. Figure 15 depicts a typical double-layer capacitor.

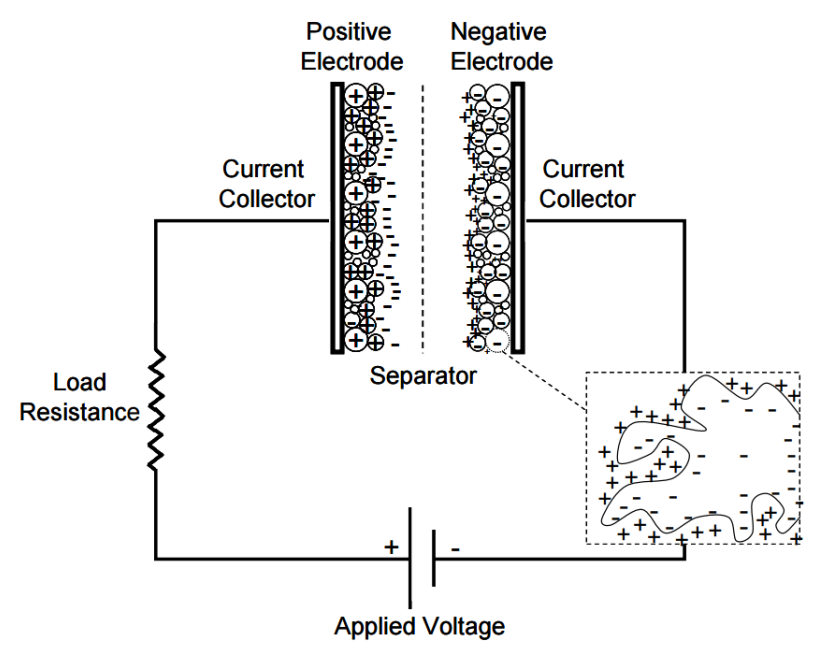

Figure 15. Schematics of a typical double-layer capacitor. [26]

When a voltage is applied to the carbon electrodes, an electric field is created between the charged electrodes making the electrically charged ions in the electrolyte migrate towards the electrodes of opposite polarity. Resulting into two separated charged layer. The reverse reaction is easy to perform due to no materials are physically affected. Charge-discharge cycles could reach above 100000.

\section{Pseudo-capacitors}

Pseudo-capacitors consist of two electrodes separated by an electrolyte. These electrodes are made from conduction polymers or metal oxides. Some advantages of 
conducting polymers are the high capacity and conductivity, low ESR and price compared to electrodes based on carbon. Disadvantage is that the lifetime is shortened if a mechanical stress is applied on the conductive polymer during charge and discharge. Ruthenium oxide pseudo-capacitors have higher energy and power densities than similar double-layer capacitors and conducting polymer pseudo-capacitors. But due to the high cost of ruthenium oxide the success has been limited. Charge storage occurs by chemical and electrostatic means. The chemical process transfers charge similar to that in a battery, i.e. by means of redox reactions. The electrostatic process is similar to that in a double-layer capacitor, i.e. by means of the electric double layer.

\section{Hybrid capacitors}

Hybrid capacitor, as the name indicates, is a hybrid between a double-layer capacitor and pseudo-capacitor. To realize better performance characteristics, hybrid capacitors try to exploit the advantages and extenuate the disadvantages of double-layer capacitors and pseudo-capacitors.

\subsubsection{Summary of Energy Storage}

Low energy density is the main flaw of supercapacitors, i.e. the amount of energy that can be stored per unit weight is very small. As can be seen in Table 3, the energy density for Li-lon batteries is approximately 3-4 times higher than for supercapacitors.

As seen in Table 2, the standard reduction potential for lithium based batteries is -3.05 $V$, which is the lowest value of all the metals in the electrochemical series. Comparing the energy densities for different battery technologies, Lithium batteries have the highest energy density of them all. This is due to lithium being the lightest of the metals.

The self-discharge rate for supercapacitors is quite high, and there are a number of different reasons for this. But the most common reason is the uncontrolled redox reaction in the electrode material. This can be solved by improving material purity of the electrodes. [26]

For easy comparison, some key properties and specifications for $\mathrm{Ni}-\mathrm{Cd}, \mathrm{Li}-\mathrm{lon}$ and supercapacitors are discussed below. 


\section{Energy density}

Energy density can be expressed in two ways: Gravimetric energy density and volumetric energy density. Gravimetric energy density shows how much energy a battery/capacitor contains in comparison to its weight. This measure is expressed in Watt-hours/kilogram $(W-h r / k g)$. The Volumetric energy density measure shows how much energy a battery/capacitor contains in comparison to its volume. This measure is expressed in Watt-hour/liter $(W-h r / l)$. Table 3 shows that the gravimetric density for LiIon batteries is larger than for $\mathrm{Ni}-\mathrm{Cd}$ batteries and supercapacitors, meaning two things: $\mathrm{Li}$-lon cells can have double the run time for the same weight as for $\mathrm{Li}$-lon, $\mathrm{Ni}-\mathrm{Cd}$ and supercapacitors, or that the Li-ion cells can be made much lighter without sacrificing run time. [28]

Table 3. Energy density for Li-lon, Ni-Cd and supercapacitor. [29] [30]

\begin{tabular}{|c|c|c|c|}
\hline Cell type & Ni-Cd & Li-lon & Supercapacitor \\
\hline $\begin{array}{c}\text { Gravimetric density } \\
\text { (W-hr/kg) }\end{array}$ & $40-60$ & $\begin{array}{c}100- \\
250\end{array}$ & $20-90$ \\
\hline $\begin{array}{c}\text { Volumetric density } \\
\text { (W-hr/l) }\end{array}$ & $50-$ & $250-$ & $1-30$ \\
\hline
\end{tabular}

\section{Self-discharge}

Table 4 shows typical self-discharge values, which are given in \%/month. The values change with manufacturer and increase as the temperature increases. Li-lon has lower self-discharge than $\mathrm{Ni}-\mathrm{Cd}$, while supercapacitors can have up to $50 \%$. [28]

Table 4. Self-discharge rates for Li-Ion, Ni-Cd and supercapacitor. [29]

\begin{tabular}{|c|c|c|c|}
\hline Cell Type & Ni-Cd & Li-lon & Supercapacitor \\
\hline Self-discharge & $10 \%$ at $20^{\circ} \mathrm{C}$ & $\begin{array}{c}8 \% \text { at } 21^{\circ} \mathrm{C}, 15 \% \\
\text { at } 40^{\circ} \mathrm{C}, 31 \% \text { at } \\
60^{\circ} \mathrm{C}\end{array}$ & Up to $50 \%$ \\
\hline
\end{tabular}

\section{Recharge time}

When charging the batteries, there is a slow charging rate and a fast charging rate. Slow charging means that a constant charging current is applied to a battery without any kind of monitoring or charge threshold method. When it comes to Li-lon cells, they will be damaged if current is continuously forced into when fully-charged. Li-lon cells are therefore charged using constant-voltage instead of constant-current to prevent damage. If fast charging is desirable the system cost will rise, due to the more complex 
charging circuitry. For supercapacitors the charge time is quite fast, due to their low internal resistance, which makes high charge and discharge currents possible. Table 5 presents typical minimum charging times given in hours for $\mathrm{Ni}-\mathrm{Cd}$ and $\mathrm{Li}-\mathrm{Ion}$ and in seconds for supercapacitors.

Table 5. Recharge time for Li-lon, Ni-Cd and supercapacitor.

\begin{tabular}{|c|c|c|c|}
\hline Cell type & Ni-Cd & Li-lon & Supercapacitor \\
\hline Slow charging time & $4-10(H R)$ & (See text) & - \\
\hline Fast charging time & $0.25-1(H R)$ & $1.5(H R)$ & $1-10$ (seconds) \\
\hline
\end{tabular}

\section{Cycle durability}

The life time of a storage element is limited by the number of charge-discharge cycles. The higher the number of cycles the higher is the likelihood of the storage element to last longer.

Table 6. Life time for Li-Ion, Ni-Cd and supercapacitor. [31]

\begin{tabular}{|c|c|c|c|}
\hline Cell type & Ni-Cd & Li-lon & Supercapacitor \\
\hline Cycle life & $100-1000$ & 500 and higher & 1 million \\
\hline
\end{tabular}




\section{Design Phase}

\subsection{Solar cells}

The solar cells used in this thesis are: two amorphous-silicon (a-Si) solar cells from Panasonic and one gallium-arsenide (GaAs) thin-film solar cell from Alta Devices. The model names of the a-Si solar cells are AM-8801 and AM-1801. Table 7 shows the properties of the solar cells under standard test condition and what kind of tests that are done with each of the solar cells. Four AM-8801 solar panels were connected in parallel when used in the final prototype. The AM-1801 was only used to demonstrate the effect of temperature on solar cells.

Table 7. Properties of solar cells under STC. [5]

\begin{tabular}{|c|c|c|c|}
\hline Properties & $\begin{array}{c}\text { a-Si } \\
(\mathrm{AM}-8801)\end{array}$ & $\begin{array}{c}\text { Alta Devices } \\
\text { GaAs }\end{array}$ & $\begin{array}{c}\text { a-Si } \\
(\mathrm{AM}-1801)\end{array}$ \\
\hline $\begin{array}{l}\text { Open circuit } \\
\text { voltage }(V)\end{array}$ & 5.2 & 1.06 & 4.9 \\
\hline $\begin{array}{l}\text { Short circuit } \\
\text { current }(m A)\end{array}$ & 38.2 & 218.5 & 0.02 \\
\hline Efficiency (\%) & 6.8 & 20.6 & 5.1 \\
\hline Module area $\left(\mathrm{cm}^{2}\right)$ & 31.8 & 8.5 & 13.3 \\
\hline \multicolumn{4}{|l|}{ Image } \\
\hline $\begin{array}{l}\text { Different test } \\
\text { done: }\end{array}$ & $\begin{array}{l}I-V \text { and } P \text {-V Curve, } \\
\text { used in final prototype }\end{array}$ & I-V and P-V Curve & Temperature \\
\hline
\end{tabular}




\subsection{Power Management IC}

This section is based on the datasheet of BQ25570 [32].

As mentioned in section 2.2, when choosing a PMIC there are some constraints and available characteristics to take into consideration. After comparing commercial available ICs on the market, the choice ended up with the power management IC $B Q 25570$ from Texas Instruments. The IC is marketed by the manufacturers as an "Ultra Low Power Harvester Power Management IC with Boost Charger, a Nanopower Buck Converter". The current consumed by the circuit itself is rated to be $488 n A$, which is one of the lowest in today's market.

The maximum power point tracking (MPPT) algorithm used is the open circuit method, described in section 2.2. The sampling of the open circuit voltage, $V_{o c}$, is done every 16 seconds by periodically disabling the charger for $256 \mathrm{~ms}$. As mentioned in section 2.2 the maximum power output voltage, $V_{M P}$, is approximately $70-80 \%$ of the open circuit voltage. The BQ25570 features the possibility to program the desired MPPT. Typically, solar cells are at their MPP when loaded $70-80 \%$ of their open circuit voltage and TEGs at $50 \%$. The IC supports input voltages down to $100 \mathrm{mV}$ and is able to output up to 5.5 $V$, to charge the storage element. To prevent damage to the storage element, there is the possibility to monitor both the maximum and minimum voltages against the internally programmed under-voltage $\left(V B A T_{-} U V\right)$ and the user programmed over-voltage (VBAT_OV) levels.

The output voltage is user programmable to output a constant voltage and in this project the output voltage was set to $3.6 \mathrm{~V}$.

To determine the VBAT_OV threshold level, the external resistors, $R_{O V 1}$ and $R_{O V 2}$, should be determined. This is done by the help of Equation (26):

$$
V B A T_{-} O V=\frac{3}{2} V B I A S\left(1+\frac{R_{O V 2}}{R_{O V 1}}\right)
$$

VBIAS is the internal reference for the programmable voltage thresholds, which is nominally $1.21 \mathrm{~V}$. There is a recommendation that the sum of the resistors should not be higher than $13 \mathrm{M} \Omega$.

The under-voltage threshold, $V B A T_{-} O V$, is internally set to $1.95 \mathrm{~V}$.

The constant output voltage is programmed by determining the external resistors $R_{\text {OUT1 }}$ and $R_{\text {OUT2 }}$, see Equation (27). Even here the sum of the resistors should not be greater than $13 M \Omega$.

$$
V O U T=V B I A S\left(\frac{R_{O U T 2}+R_{O U T 1}}{R_{O U T 1}}\right)
$$

The IC consists of a boost controller at the input and a buck controller at the output. The boost controller steps up the voltage from the solar cell if needed, while the buck controller steps down the voltage to a regulated voltage at the output. 


\subsection{Energy Storage}

As storage solution to this work, double layer supercapacitors are used as storage elements. The supercapacitors used are the PHV-5R4V255- $R$ from BUSSMANN BY $E A T O N$, with a capacitance of $2.5 F$, with a voltage rating of $5.4 \mathrm{~V}$ and a maximum $E S R$ measured at $1 \mathrm{kHz}$ at $0.08 \Omega$. In the final prototype the energy storage consists of six $\mathrm{PVH}-5 \mathrm{R} 4 \mathrm{~V} 255-\mathrm{R}$ supercapacitors connected in parallel, resulting in a total capacity of $15 \mathrm{~F}$ and the same voltage rating. [33]

Supercapacitors were chosen due to the high number of charge-discharge cycles and the specification of this project was that supercapacitors should preferably be used as storage element.

\subsection{Schematic of prototype}

The schematic of the final prototype can be found in section A.1. The schematic was drawn by a consultant that was hired to help with the drawing of printed circuit board (PCB) layout and soldering components to the prototype.

The power management circuitry was inspired from the datasheet of BQ25570. There were some adjustments made for our needs and available stock from the electronic component supplier.

The top- and bottom layer of the PCB can be seen in Figures 17 and 18. The top layer was used for placements of components while the bottom layer was used for ground purpose. To avoid instability and/or electromagnetic interference problems with the boost and buck converters, some consideration was made with the layout design. That is, the placement of the output and input inductors and capacitors were placed as close as possible to the IC, denoted as IC1 in Figure 16. Figure 16 shows the PCB top assembly, were the placement of capacitors $C 4, C 3, C 1$ and $C 5$ are close to the IC as well as for the inductors $L 1$ and $L 2$. To minimize the pickup of noise, the external resistors, $R_{O V 1}, R_{O V 2}, R_{O U T 1}, R_{O U T 2}, R_{O K 1}, R_{O K 2}$ and $R_{O K 3}$, were placed so that the traces connecting the midpoint of each divider to their respective pins were as short as possible. [32]

TP1 is the test point for the input voltage (VIN), TP4 is the test point for the capacitor voltage (VCAP) and TP5 stands for the test point for the constant output voltage (VOUT), which can be seen in Figure 16. These test points were installed for verification purpose. 


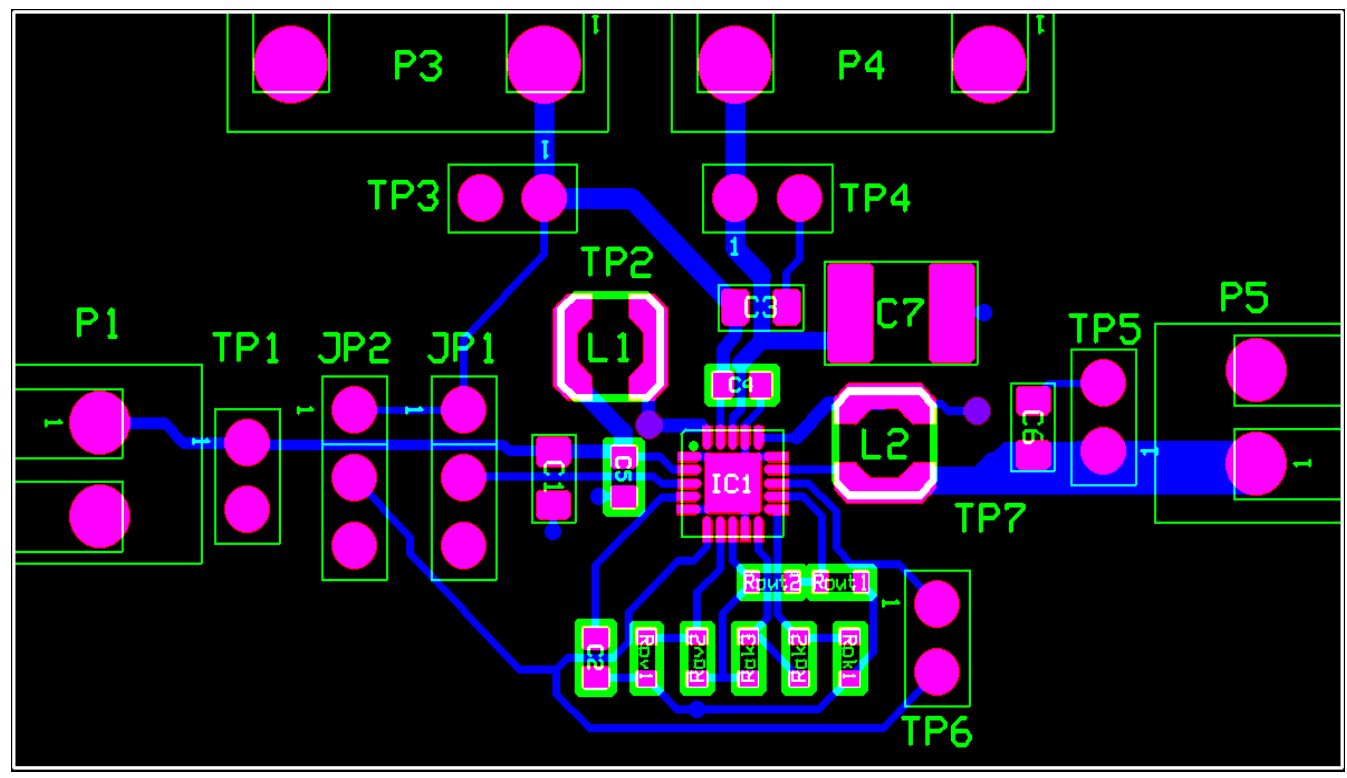

Figure 16. PCB top assembly.

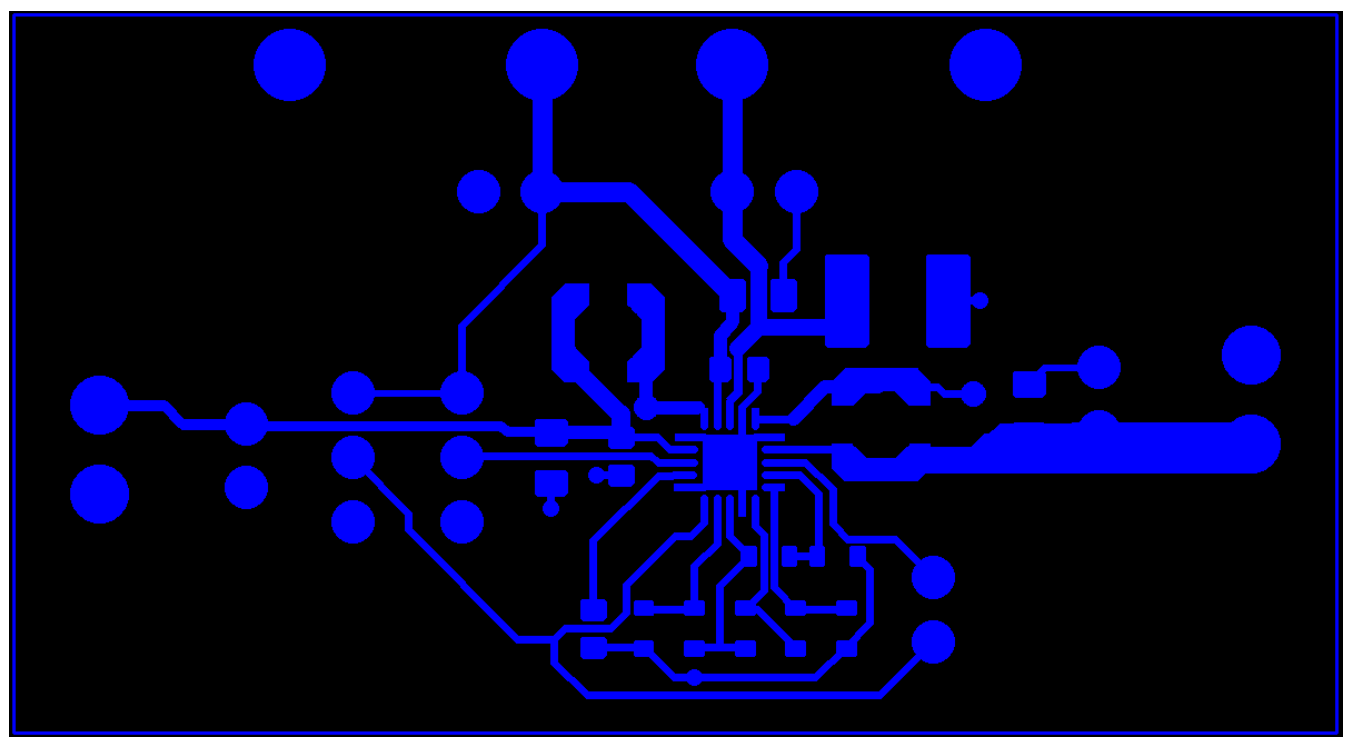

Figure 17. Top layer of the PCB. 


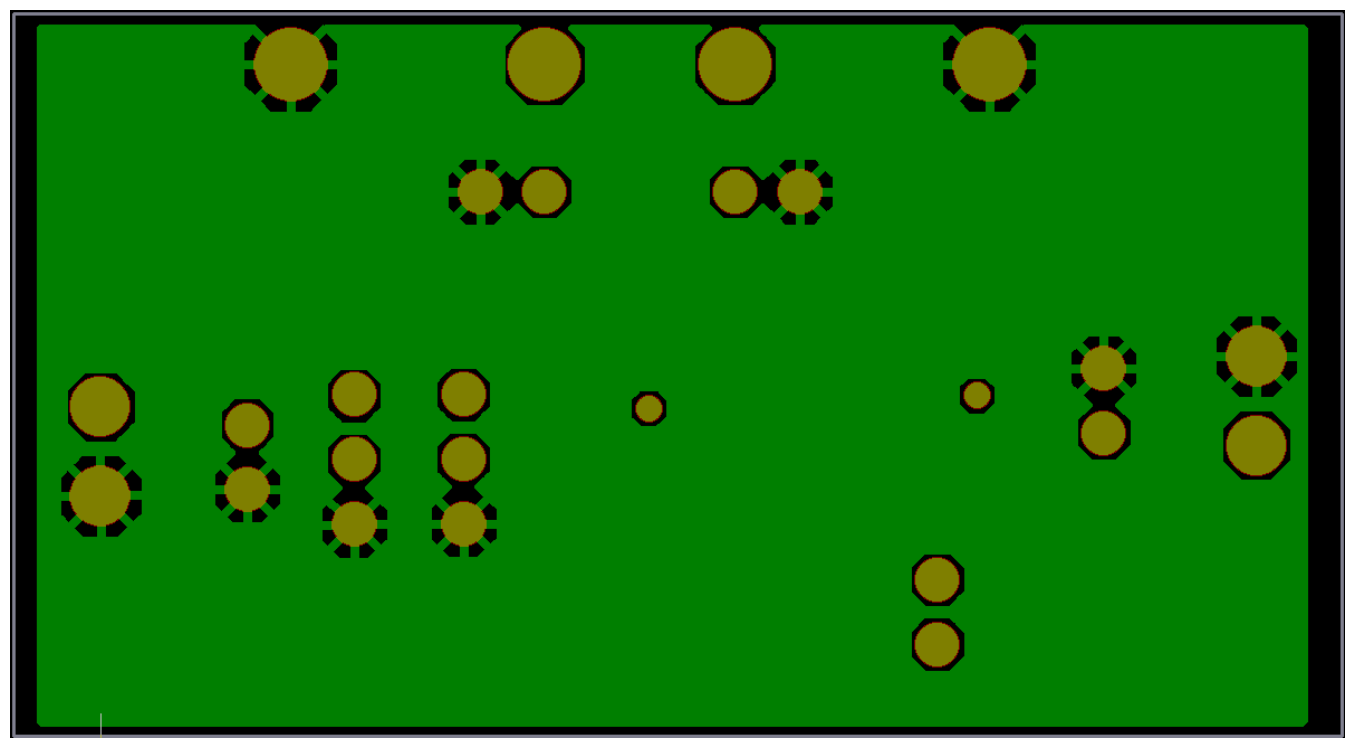

Figure 18. Bottom layer of the PCB.

The BQ25570 came in a 3.5- $\mathrm{mm} \times 3.5-\mathrm{mm}$ quad flat no-lead package, which was hand soldered with hot air to the board. The other components were soldered with a solder. A complete bill of materials (BOM) for the prototype can be found in section A.2.

Figure 19 shows a schematic of the final prototype.

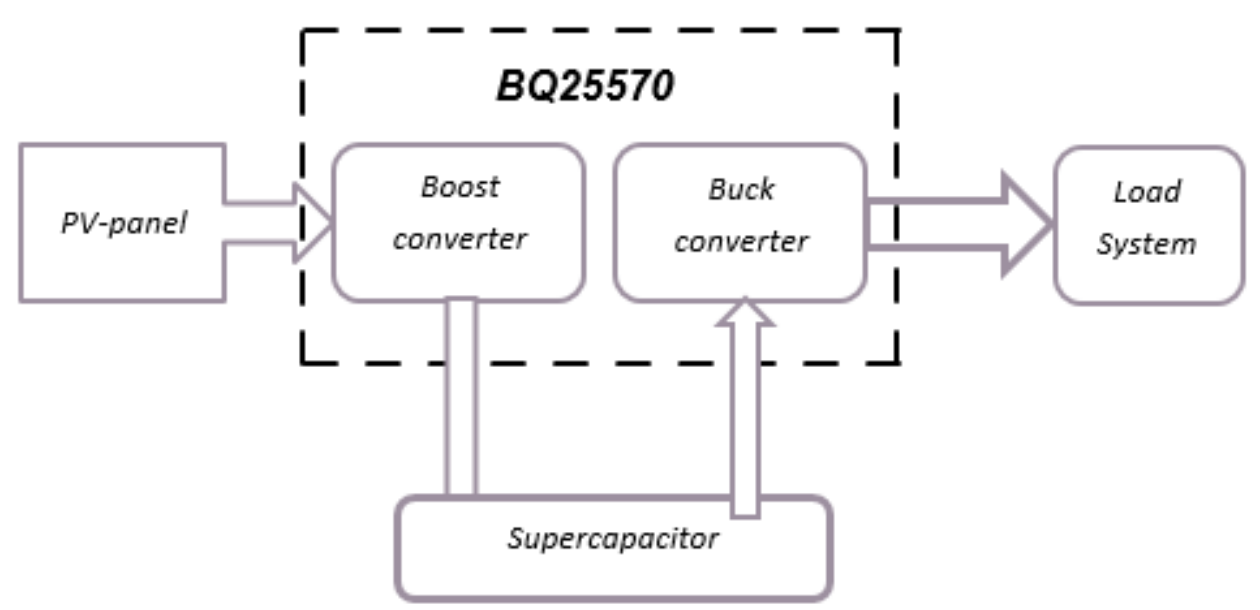

Figure 19. Schematic of final prototype. 


\section{Measurements and Results}

\subsection{I-V and P-V curves of solar cells}

Specifications of a solar cell given by manufacturers are all measurements under STC. To understand how much power can be generated by solar cells under artificial illumination at light intensities typical for indoor spaces, measurements with different illumination sources have to be done. The setup for doing these measurements are: illumination source (LED: Vossloh Schwabe, WU-M-295-W, 5400 K, 150 lumen, 5-W white LED module or Incandescent: Appliance, A15, $2700 \mathrm{~K}$, 400 lumen, 40- $W$ bulb), a current-voltage (I-V) measurement setup, Lux meter (Amprobe LM-120, $\pm 5 \%$ accuracy) and a temperature controlled climate cabinet (Thermotron) where all measurements are done, see Figure 20.

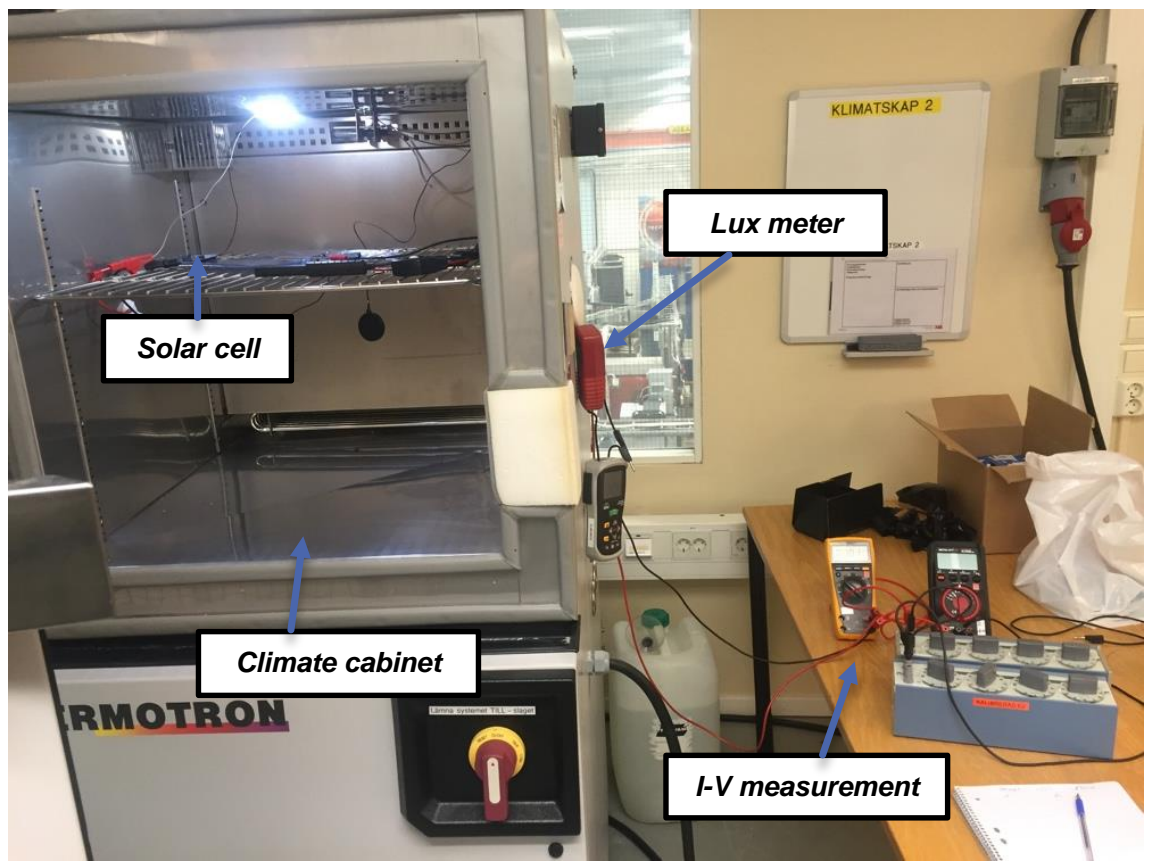

Figure 20. The test equipment. To the left the climate cabinet, with Lux meter sensor and solar cell. To the right a variable resistor, an ampere meter and a volt meter.

As seen in the figure above the current-voltage measurement setup was done with two multimeters and a variable resistor. The schematic of the setup can be seen in Figure 21 , were the PV-panel is connected to a variable resistor in series with an amperemeter and a voltage-meter is connected in parallel directly to the PV-panel. 


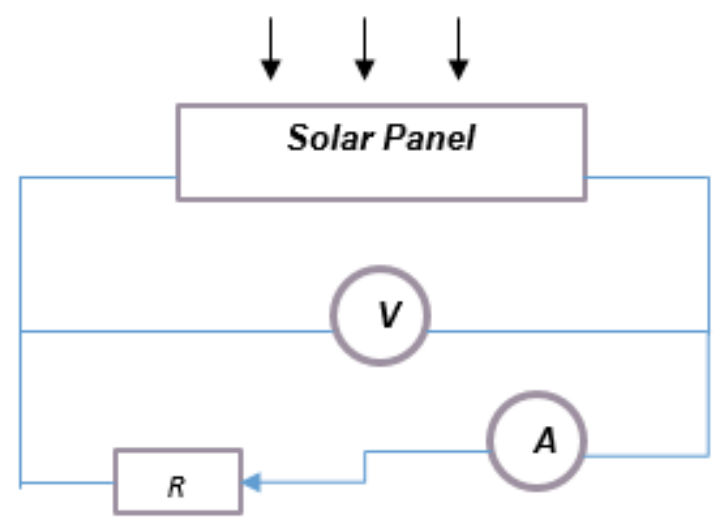

Figure 21. I-V measurement schematic.

The light intensity on the PV-panel was set by adjusting the position of the PV-panel until the right intensity was attained. The measurements were taken at 200, 400, 600 and 1000 Lux. This Lux range was used to mimic the expected illumination conditions in an office environment. [5] In a practical situation, the light intensity might change if for example the PV-panel is placed near a window. This changes the light intensity to greater levels.

The voltage and current values were measured and noted after changing the resistor value. The resistor was set to its minimum value of $0 \Omega$, which gave the short circuit current, $I_{S C}$, and was slowly turned up until the open circuit voltage, $V_{O C}$, was found. This can be verified by Ohm's law, $U=R * I$. When the resistance is large the voltage is also large while the current is small, and vice versa when the resistance is small. By multiplying the currents with the voltages the power was determined.

These measurements were done first with the LED module as illumination source and then repeated with the Incandescent bulb.

Figures 22 and 23 depict the I-V and P-V curves for the GaAs PV-cell from Alta Devices exposed to $600 \mathrm{Lux}$ at $25^{\circ} \mathrm{C}$, where Figure 22 is with an Incandescent bulb and Figure 23 is with a LED module. The blue line shows where the maximum power point is, and as mentioned in section 2.1.1.3, the MPP can be found. When the Incandescent bulb was used as light source the measured open circuit voltage was $0.890 \mathrm{~V}$ and the MPP was at $0.720 \mathrm{~V}$, which fits well with the theory. The maximum generated power was $\sim 1.720 \mathrm{~mW}$, i.e. $\sim 0.202 \mathrm{~mW} / \mathrm{cm}^{2}$.

With LED the open voltage value was $0.789 \mathrm{~V}$ and the MPP was at $0.641 \mathrm{~V}$. The maximum generated power was $\sim 0.293 \mathrm{~mW}$, i.e. $\sim 0.035 \mathrm{~mW} / \mathrm{cm}^{2}$. The big difference in maximum generated power using Incandescent bulb versus LED is due to the large larger radiation spectra from Incandescent light. 


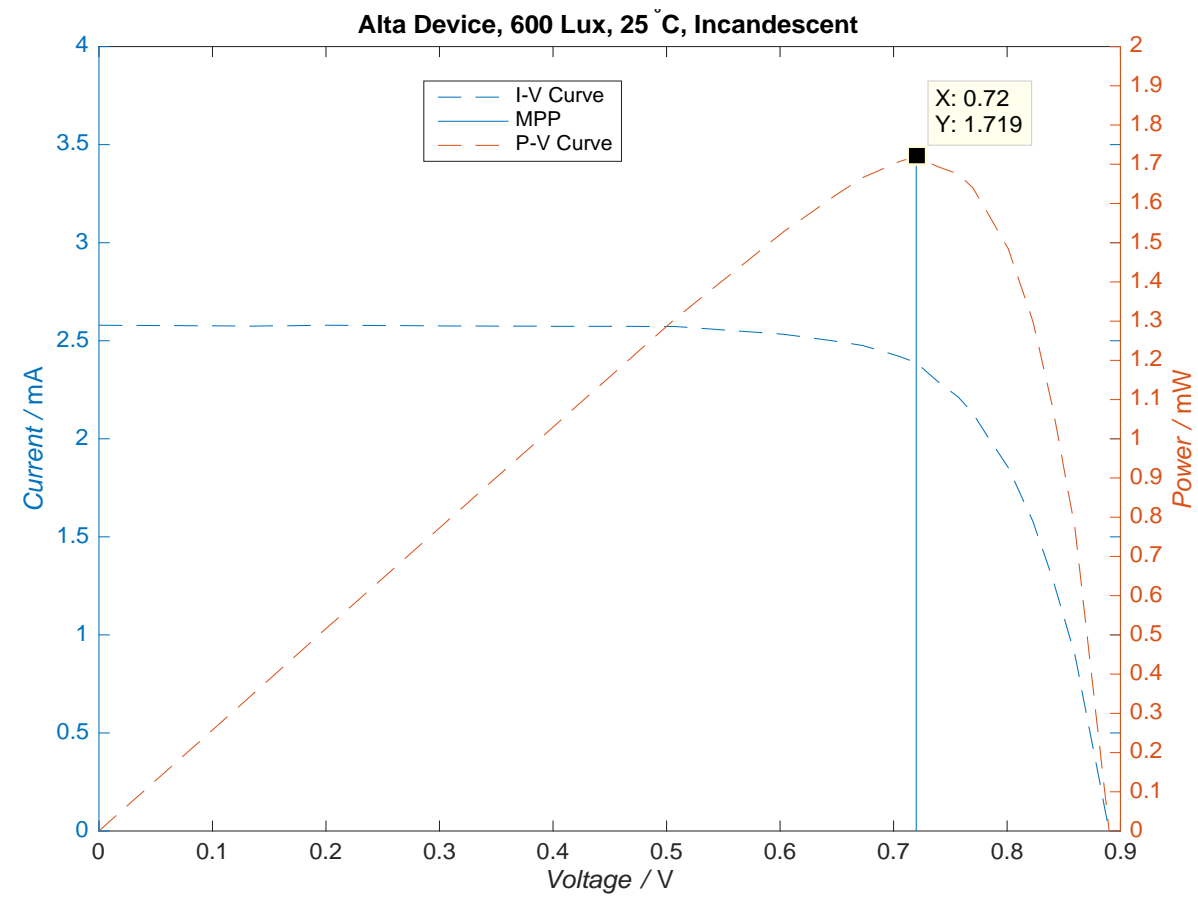

Figure 22. I-V and P-V curves for solar cell from Alta Devices exposed to a light intensity of 600 Lux with an Incandescent bulb.

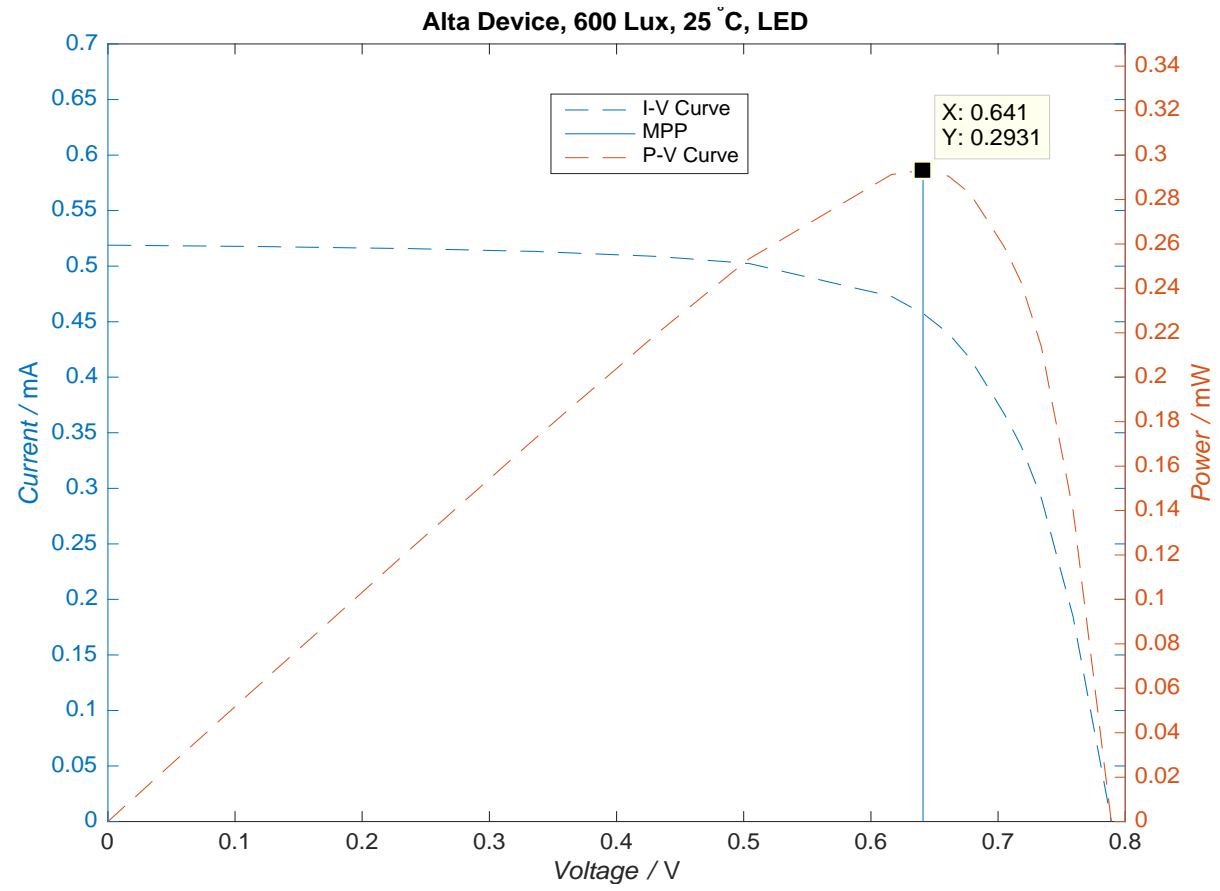

Figure 23. I-V and P-V curvse for solar cell from Alta Devices exposed to a light intensity of 600 Lux with a LED module. 
Figures 24 and 25 depict the I-V and P-V curves for AM-8801 from Panasonic exposed to $600 \mathrm{Lux}$ at $25^{\circ} \mathrm{C}$, where Figure 24 is with an Incandescent bulb and Figure 25 is with a LED module. When an Incandescent bulb was used as light source the measured open circuit voltage was $4.281 \mathrm{~V}$ and the MPP was at $3.074 \mathrm{~V}$, which fits well with the theory. The maximum generated power was $\sim 0.524 \mathrm{~mW}$, i.e. $\sim 0.0165 \mathrm{~mW} / \mathrm{cm}^{2}$. With LED the open voltage value was $4.098 \mathrm{~V}$ and the MPP was at $2.879 \mathrm{~V}$. The maximum generated power was $\sim 0.4339 \mathrm{~mW}$, i.e. $\sim 0.0136 \mathrm{mw} / \mathrm{cm}^{2}$. The difference in maximum generated power with this solar cell is not as large as with the Alta Devices solar cell. This is due to different absorptions edge from the solar cells.

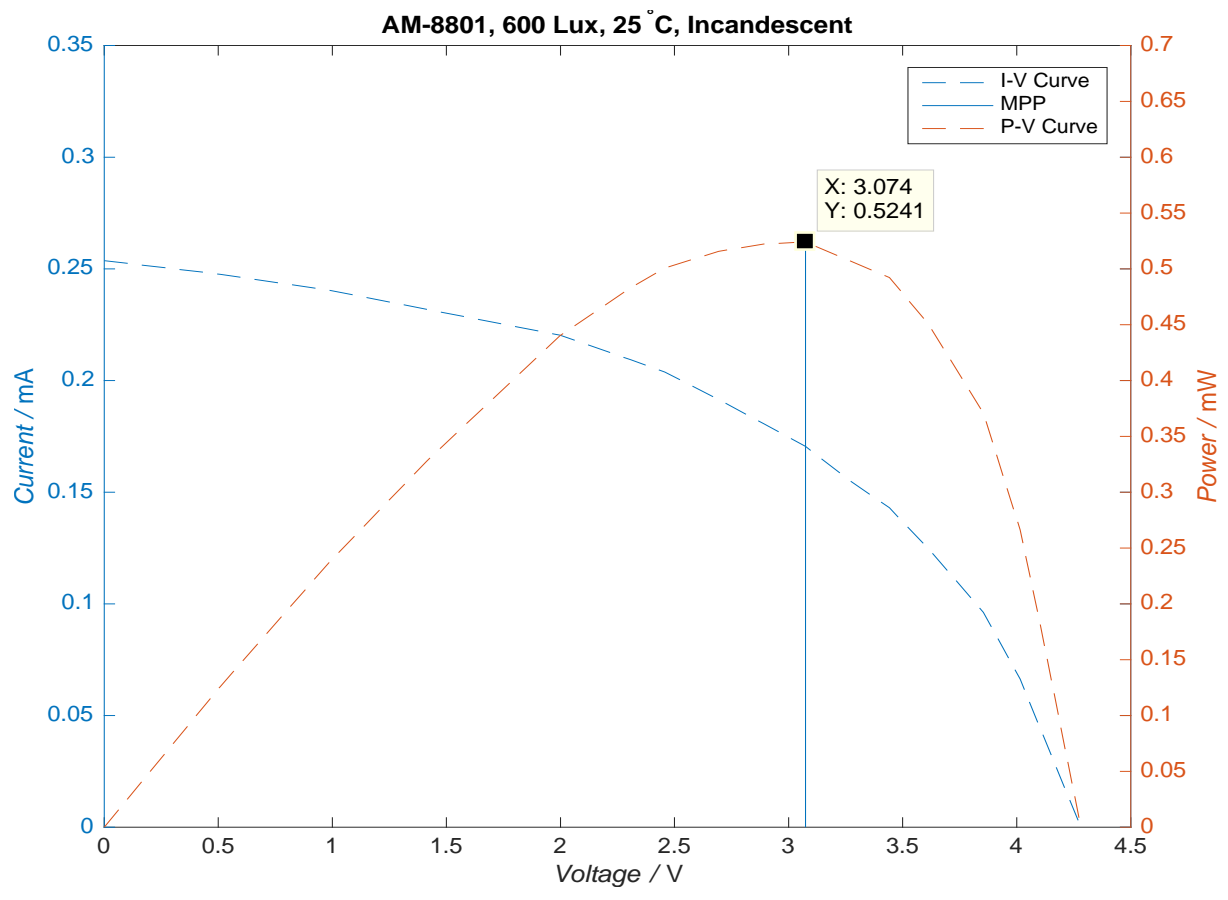

Figure 24. I-V and P-V curves for solar cell from Panasonic exposed to a light intensity of 600 Lux with an Incandescent bulb. 


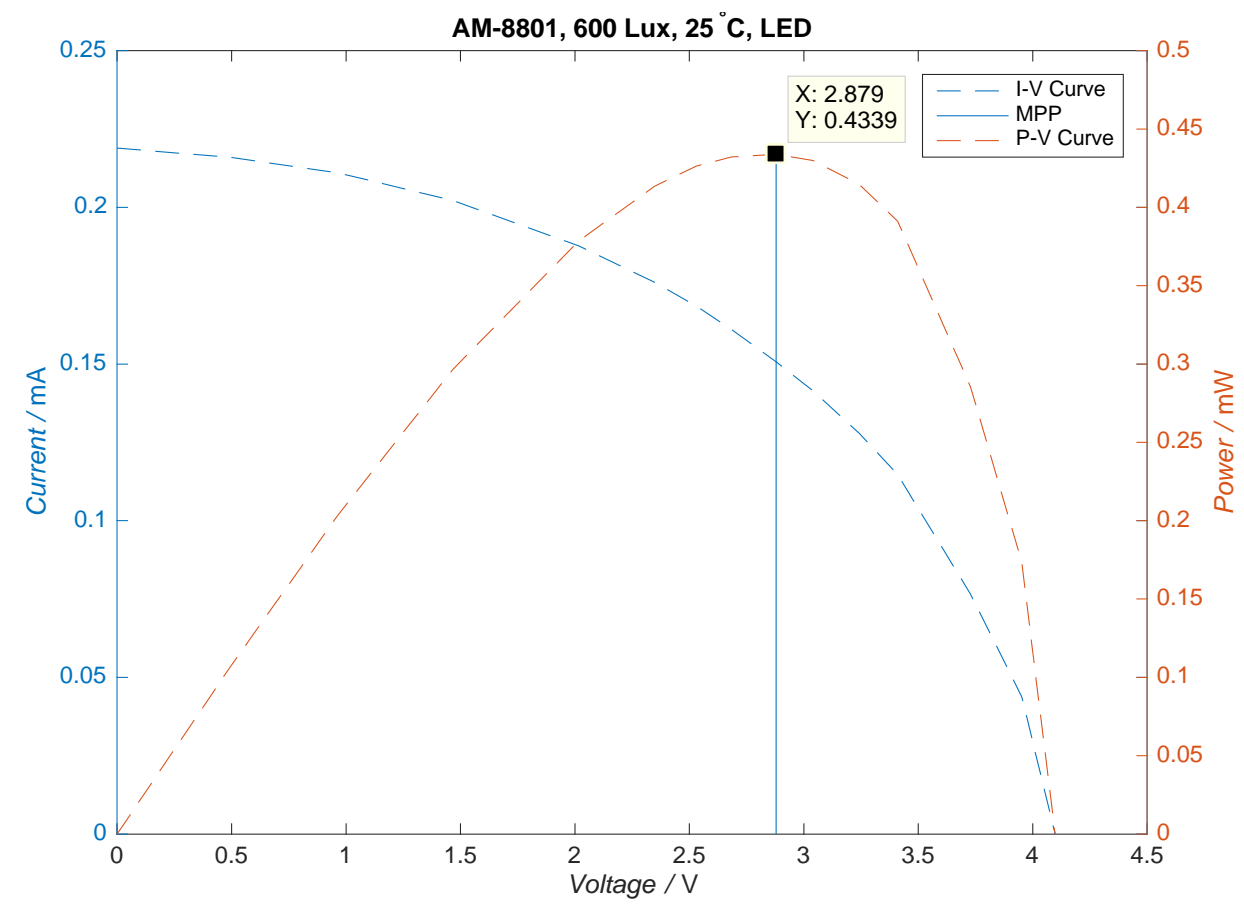

Figure 25. I-V and P-V curves for solar cell from Panasonic exposed to a light intensity of 600 Lux with a LED module.

To avoid making figures for all the light intensities and for two different lightning sources, two figures are made that depict the power outputs as a function of light intensity for the two solar cells. The power outputs are plotted as power density, i.e. maximum power output per square centimeter $\left(\mathrm{mW} / \mathrm{cm}^{2}\right)$. The power density shows how large the area of the specific solar cell has to be to get the desired power output. Figure 26 depicts the power density as a function of light intensity exposed to LED illumination at $25^{\circ} \mathrm{C}$, while Figure 27 shows the results using an Incandescent bulb as illumination at $25^{\circ} \mathrm{C}$. 


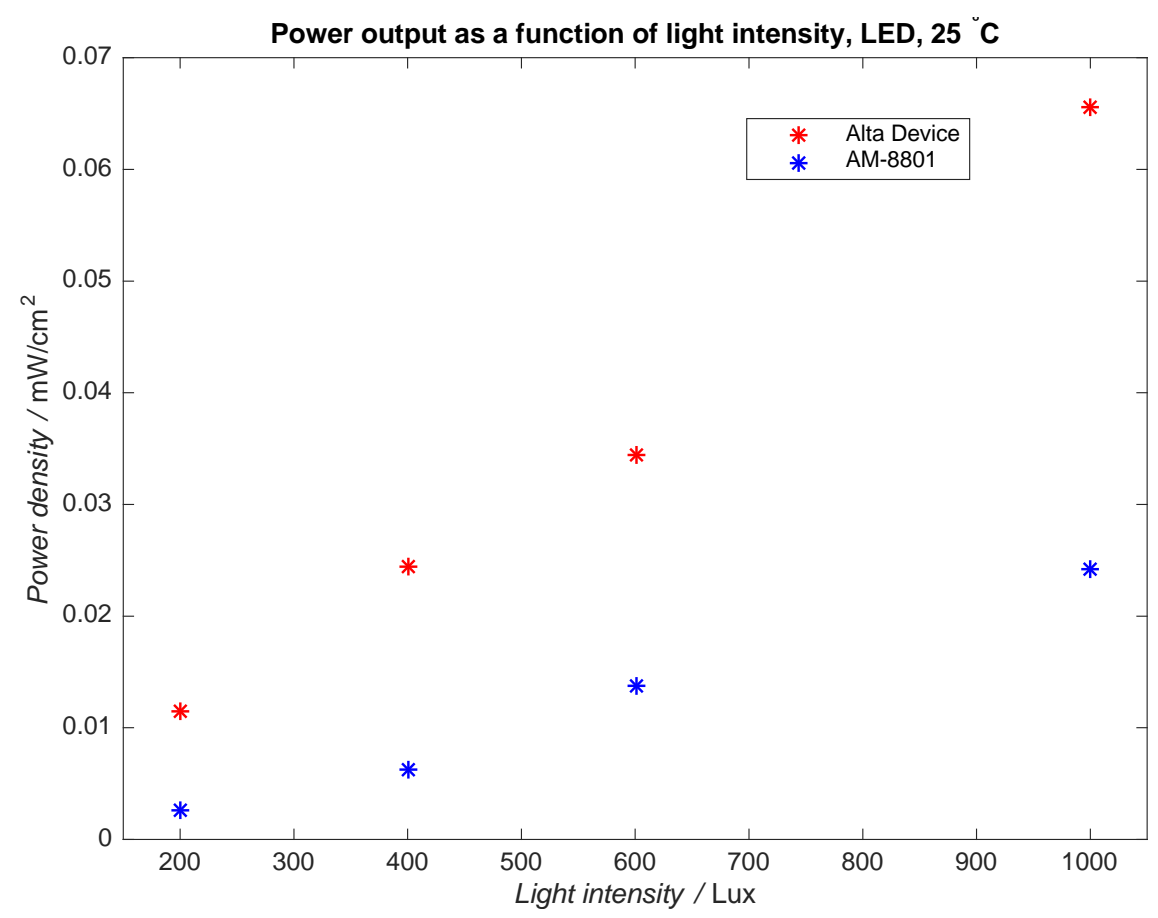

Figure 26. Power density as a function of light intensity exposed to LED illumination.

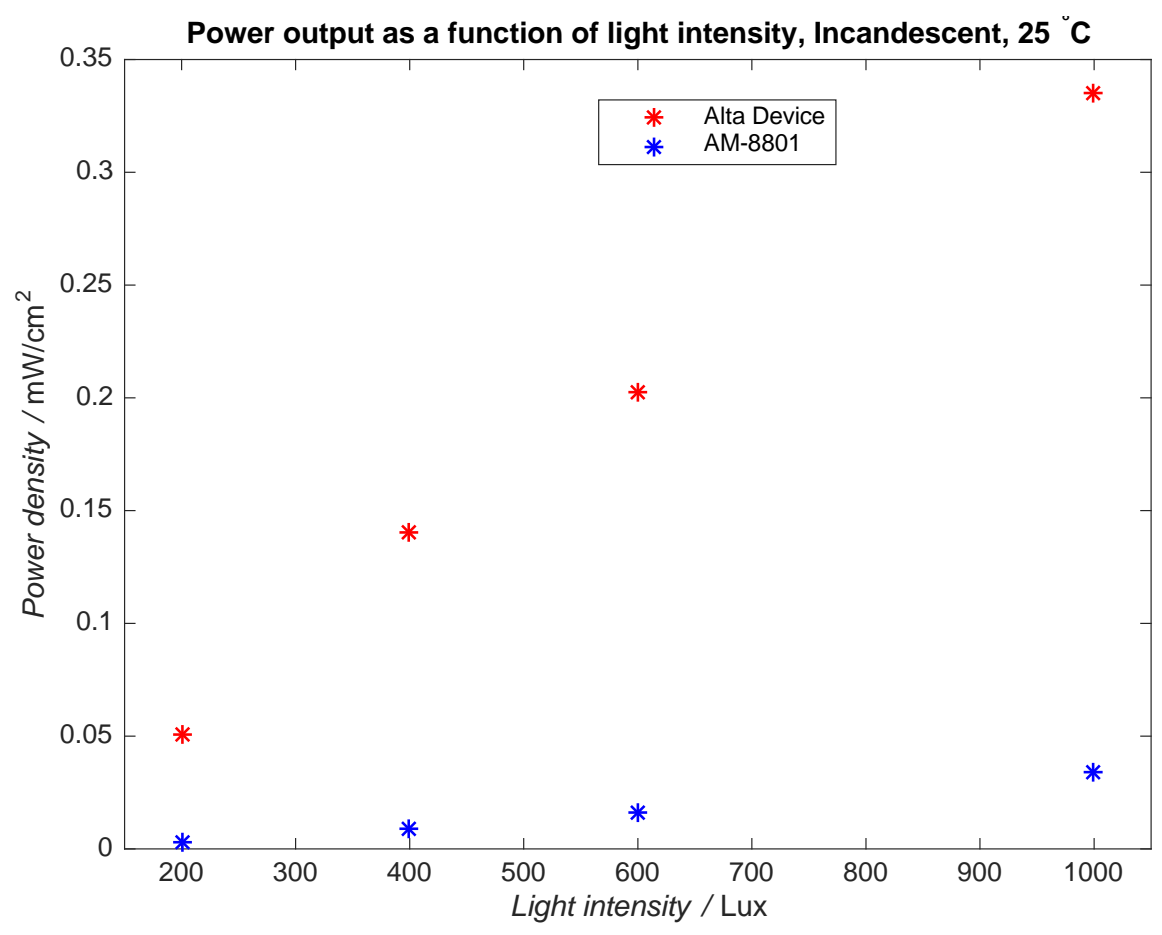

Figure 27. Power density as a function of light intensity exposed to Incandescent illumination. 
As mentioned in section 2.1.1.3 the increase of temperature on a solar cell results in a decrease of the voltage. This means that the power will also drop. To prove this, the AM-1801 solar cell was exposed to temperatures of 25,40 and $55^{\circ} \mathrm{C}$. For each temperature, the same procedure as described above was done to provide the I-V curve of this solar cell. This made it possible to obtain the maximum power.

Figure 28 shows the power density as a function of temperature exposed to LED illumination with light intensity of 1000 Lux. This confirms the decrease of output power with increase of temperature on solar cells.

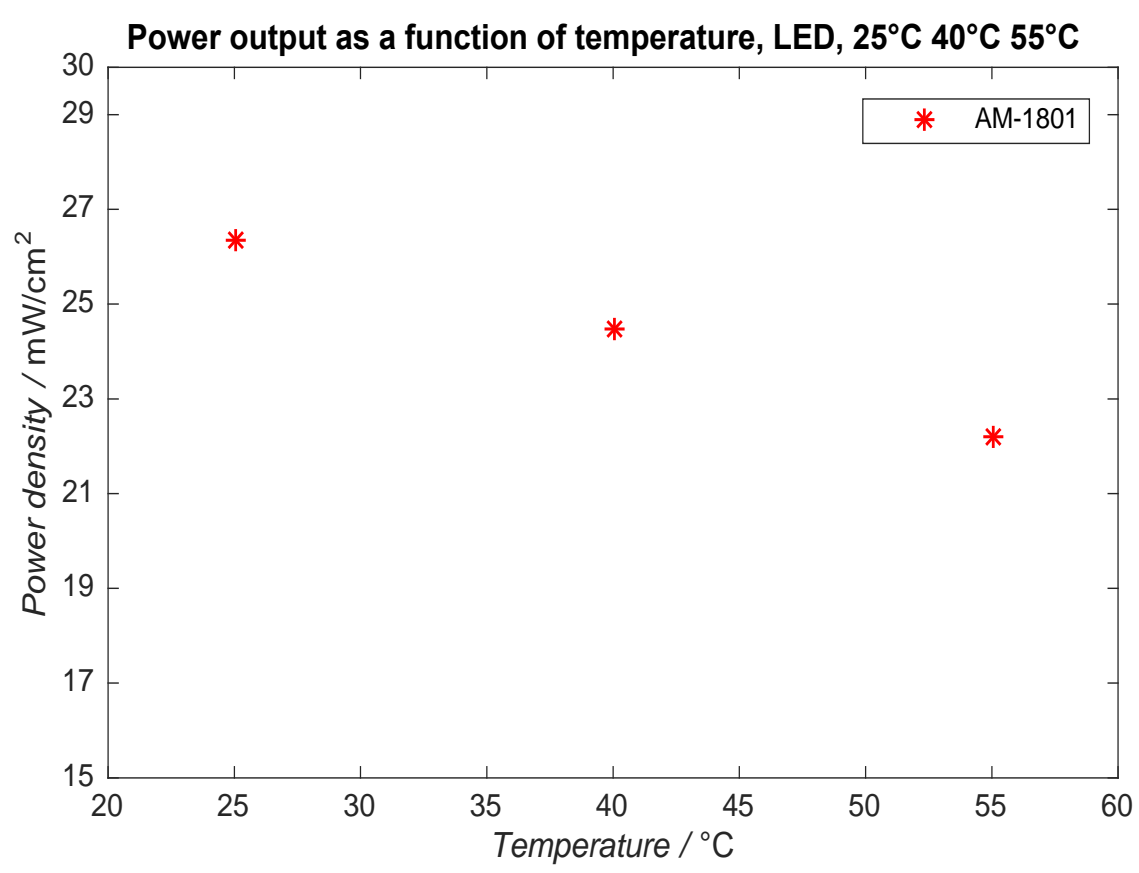

Figure 28. Power density as a function of temperature exposed to LED illumination. 


\subsection{Charge- and discharging-time of the supercapacitor}

These tests are done with four AM-8801 connected in parallel, forming a total area of $127.2 \mathrm{~cm}^{2}$. The measurements were done with LED as light source and a light intensity of $600 \mathrm{Lux}$ at $25^{\circ} \mathrm{C}$. To know the maximum power that this solar panel can produce at the given conditions, Figure 26 concludes that when exposed to 600 Lux the AM-8801 has a power density of $0.01364 \mathrm{~mW} / \mathrm{cm}^{2}$, which by multiplying with the total area of the four AM-8801 will give a maximum power of $\sim 1.73 \mathrm{~mW}$.

As mentioned in section 3.3, the energy storage was constructed by six PHV-5R4V255$R$ supercapacitors connected in parallel. The starting voltage of the supercapacitor was set to $3.6 \mathrm{~V}$ because the desired output voltage to the system load was set to this value by Equation (27) and the over-voltage protection, $V B A T_{-} O V$, of the supercapacitor was set to $5.1 \mathrm{~V}$ by using Equation (26). But to save some time due to the exponential charging behavior of a capacitor the charging stopped at $4 \mathrm{~V}$. The charging time from 3.6 to $5.1 \mathrm{~V}$ can be held by extrapolating the points.

As the system load a variable resistor was installed to simulate the SMB. The resistance was chosen so that $1 \mathrm{~mW}$ was drained from the resistor, resulting in only $\sim 0.73 \mathrm{~mW}$ available for charging the supercapacitors, see Figure 29.

The time to failure when all inputs are disconnected is determined by the time to discharge the supercapacitor from 5.1 to $3.6 \mathrm{~V}$. 


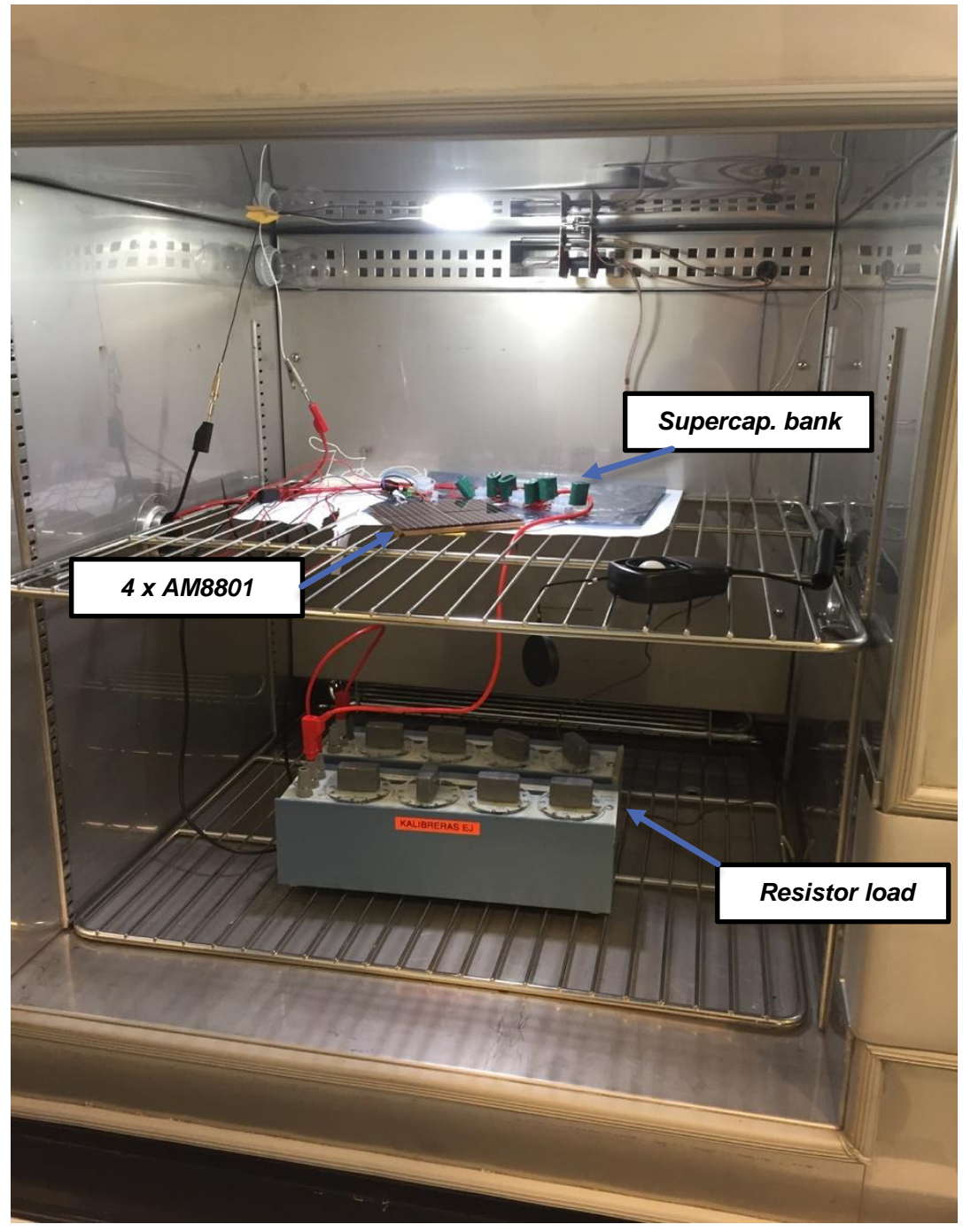

Figure 29. The setup when testing charge- and discharge-time with resistor as system load.

The test points TP4 and TP5, as can be seen in Figure 16, were connected to a data logger during the charge- and discharge-time to monitor the output voltage and the supercapacitor-voltage. Figure 30 shows the charging behavior of the supercapacitor connected to the PCB with a resistor as the system load draining a constant power of 1 $\mathrm{mW}$, while Figure 31 shows the discharging behavior. 


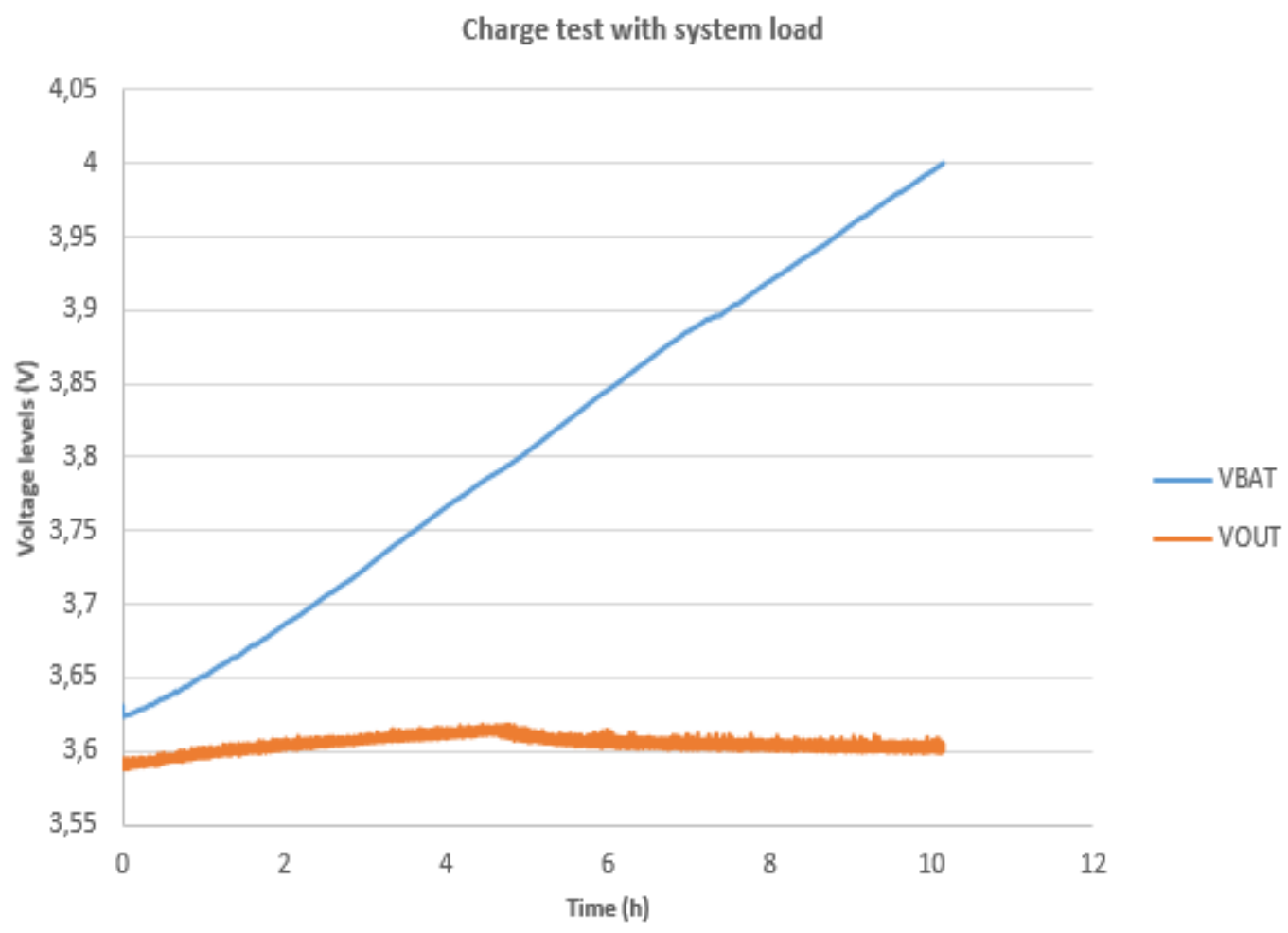

Figure 30. Charge-time for supercapacitor bank exposed to light intensity of 600 Lux and $\sim 1.73 \mathrm{~mW}$ of input power.

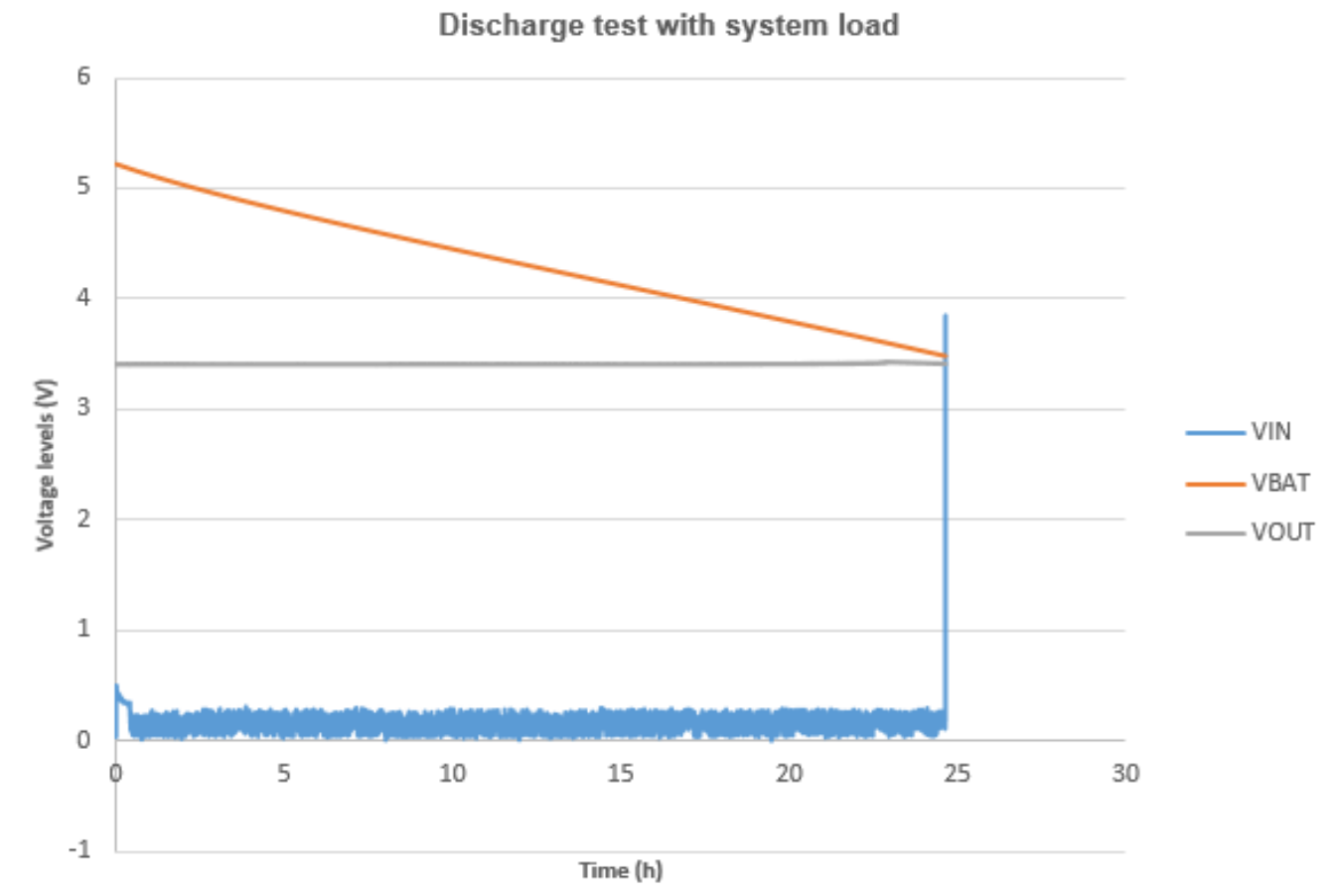

Figure 31. Discharge-time for supercapacitor bank with resistor as system load draining $1 \mathrm{~mW}$. 


\subsection{Test with SMB}

Instead of doing tests with the SMB on a robot, $A B B$ had a rack which simulated a robot, which made the SMB easier to reach, see Figure 32 . The light intensity was measured at $\sim 700$ Lux. Figure 33 shows the charging behavior of the supercapacitor bank connected to the PCB with the SMB as the system load, while Figure 34 shows the discharging behavior.

To be sure that the SMB is on and fully working, low-current measurements had to be done on the SMB. However, due to the SMB producing low-impulse currents and noise it was hard to catch them with an oscilloscope. The way around this was by using ABB's IRC5 robot controller. When turning the simulated robot on an Event Message should appear if the SMB at some point lost its power supply. Figure 35 shows how such an Event Message would look like. If no Event Message would appear then the SMB was active and fully working.

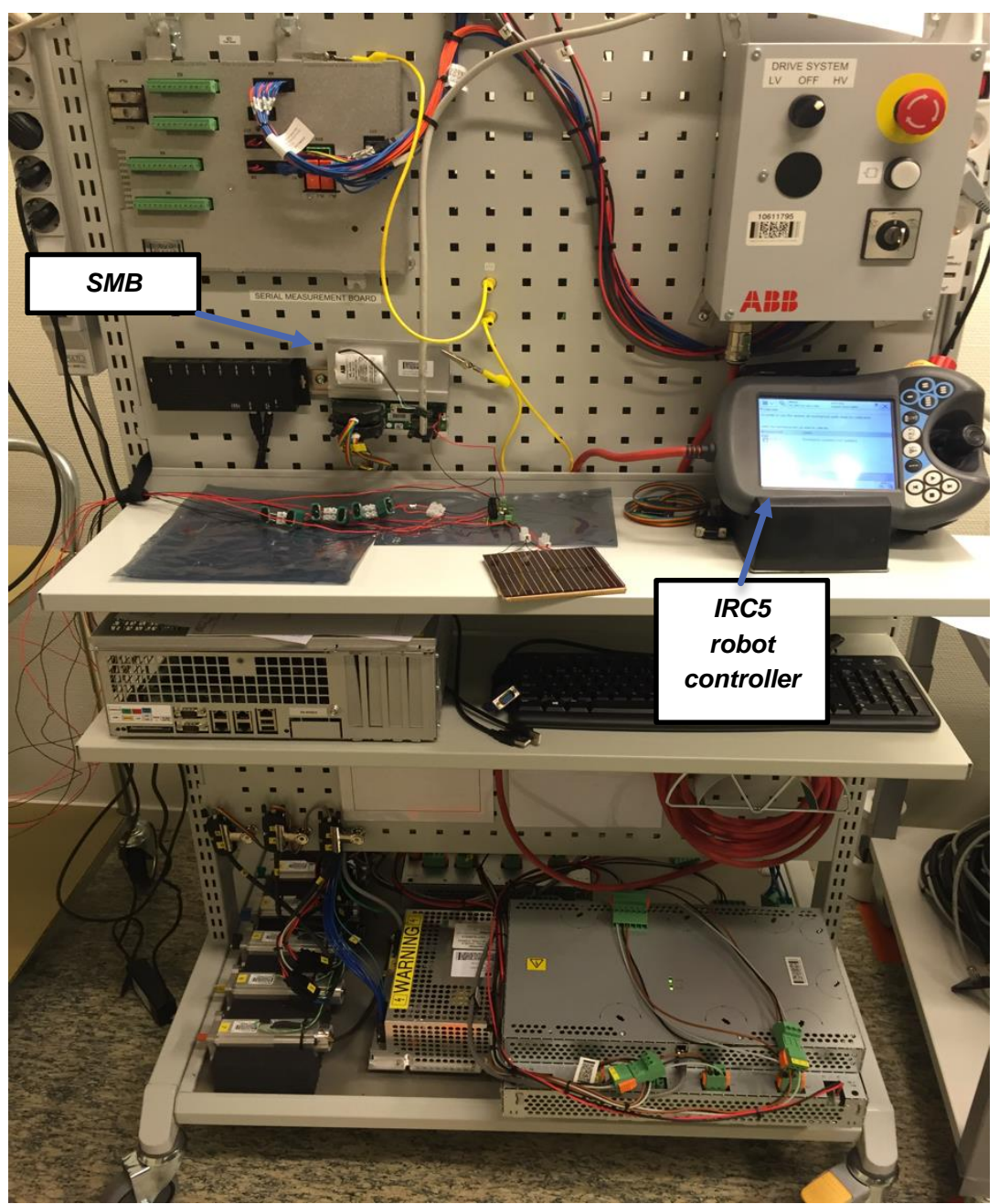

Figure 32. Test rack where tests on the SMB were done. 
Charge test with SMB

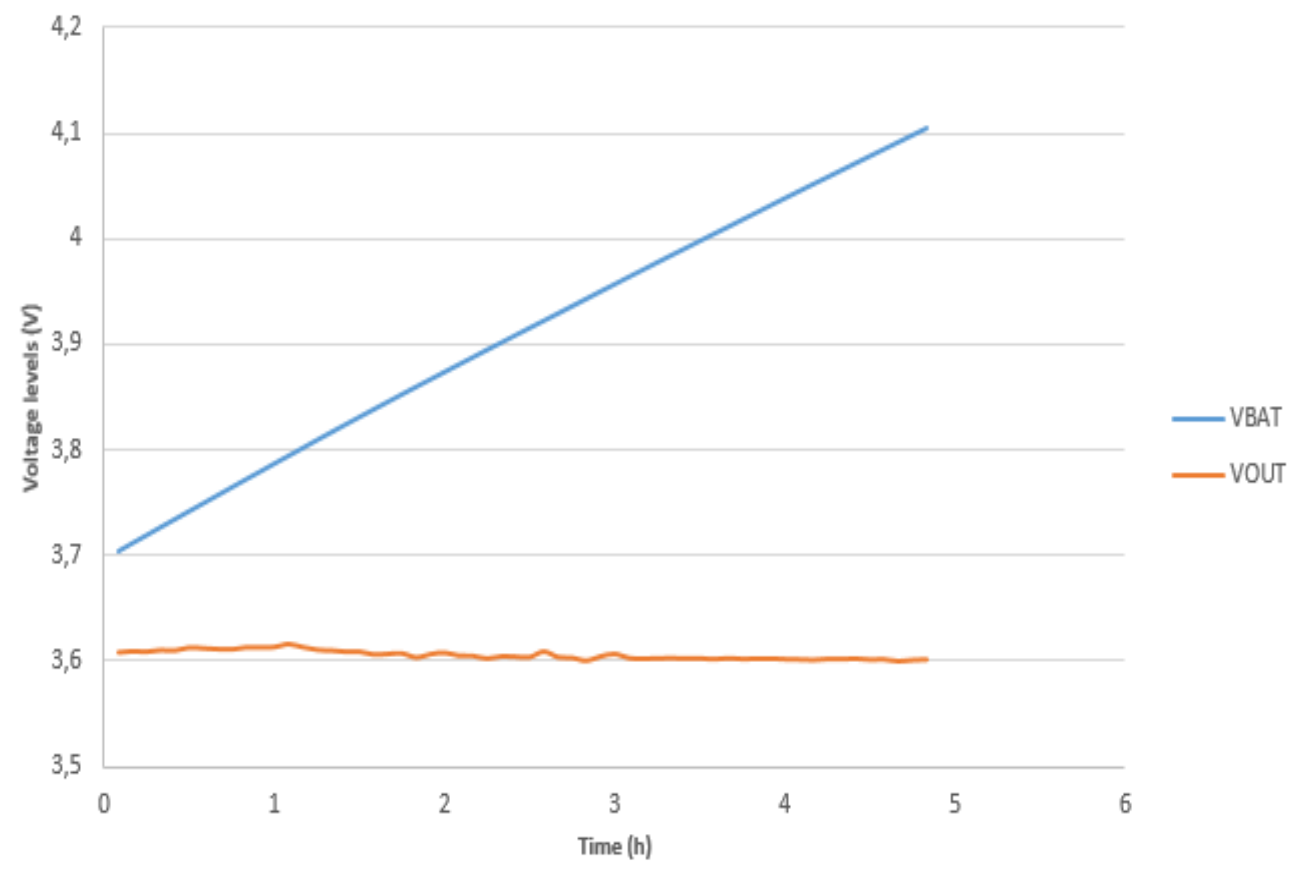

Figure 33. Charge-time for supercapacitor bank exposed to light intensity of 700 Lux.

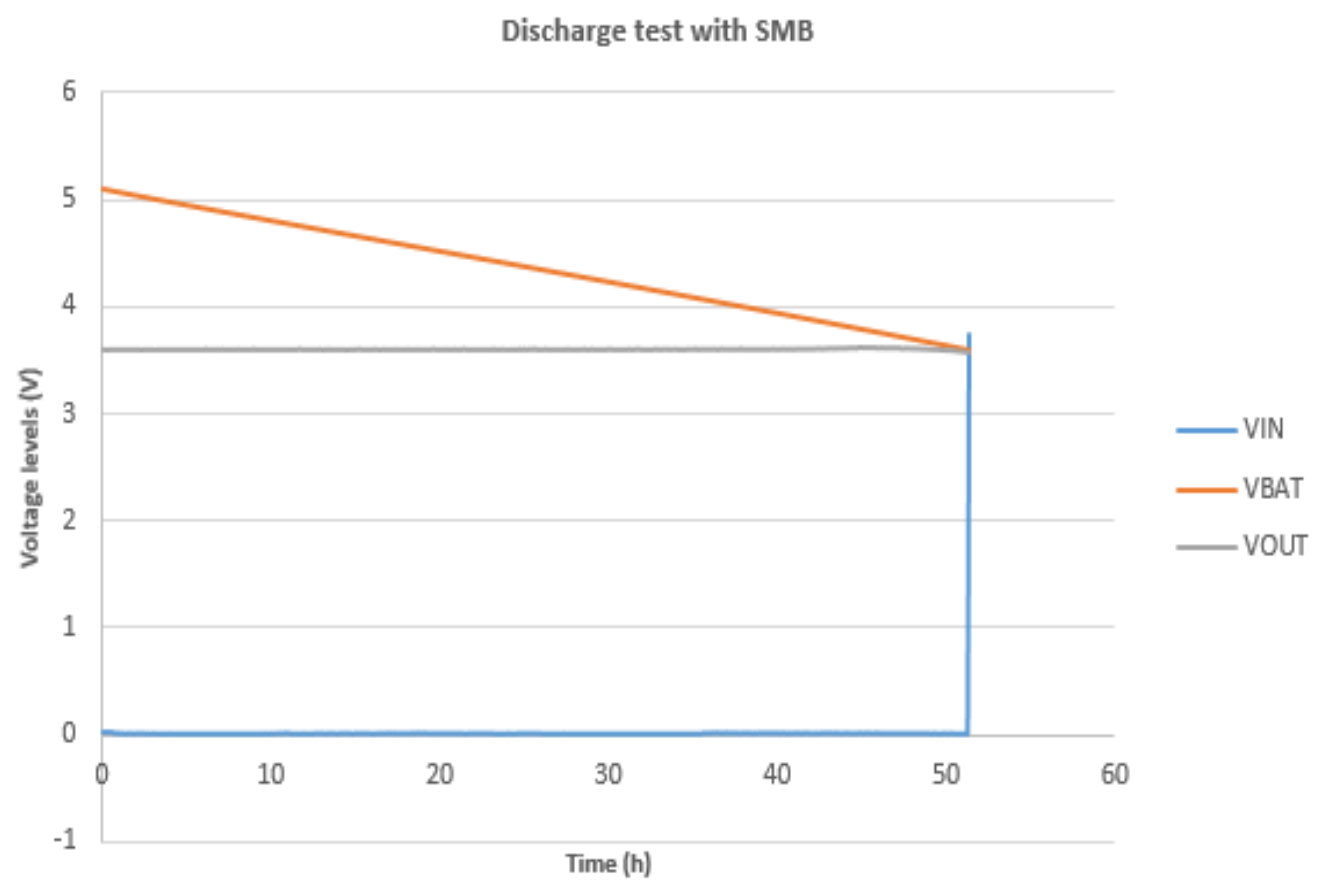

Figure 34. Discharge-time for supercapacitor bank with SMB as system load draining maximum 1 mW. 


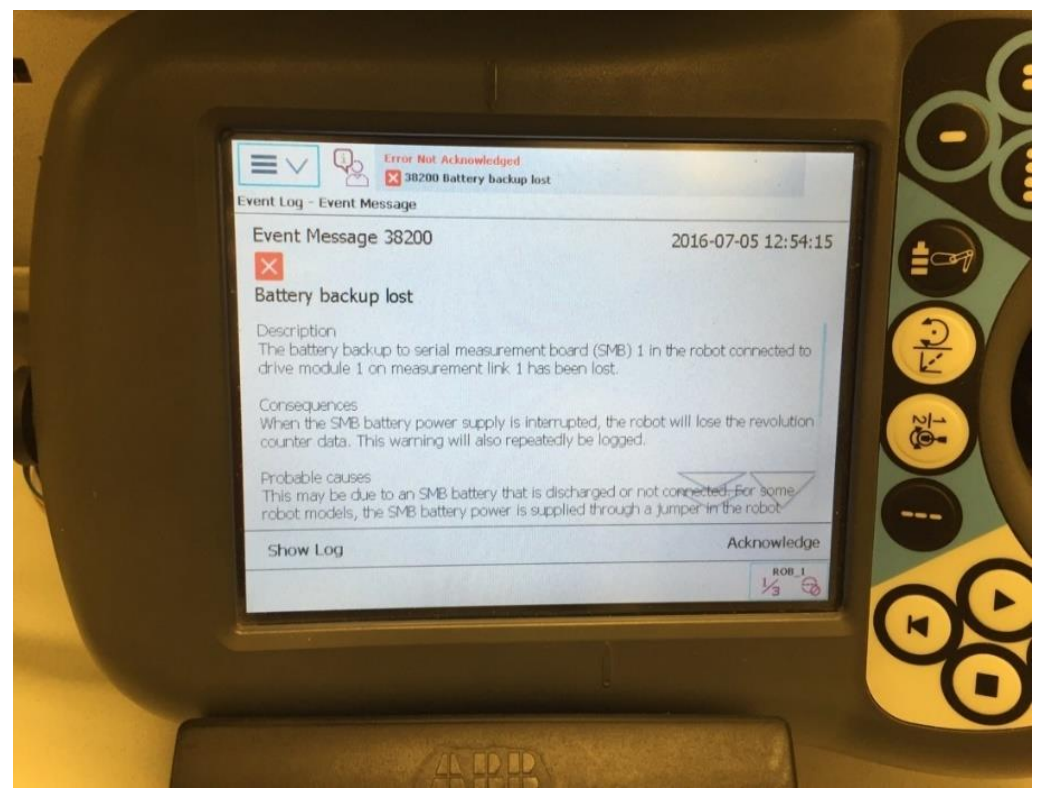

Figure 35. IRC5 robot controller to determine if power supply to the SMB was lost during Battery mode.

Figure 36 depicts the test done with the SMB for 3 weeks. As can be seen in the figure the output voltage to the SMB, VOUT, is set to $3.6 \mathrm{~V}$ and by looking at VBAT, the overvoltage threshold (VBAT_OV) can be found at $5.1 \mathrm{~V}$. The voltage from the solar cells, VIN, is zero when no source is available and increases when there is, which the figure demonstrates well. The ripple in VIN is due to the sampling of the open circuit voltage every 16 seconds. The three dips in the VOUT voltage are discussed in the coming chapter.

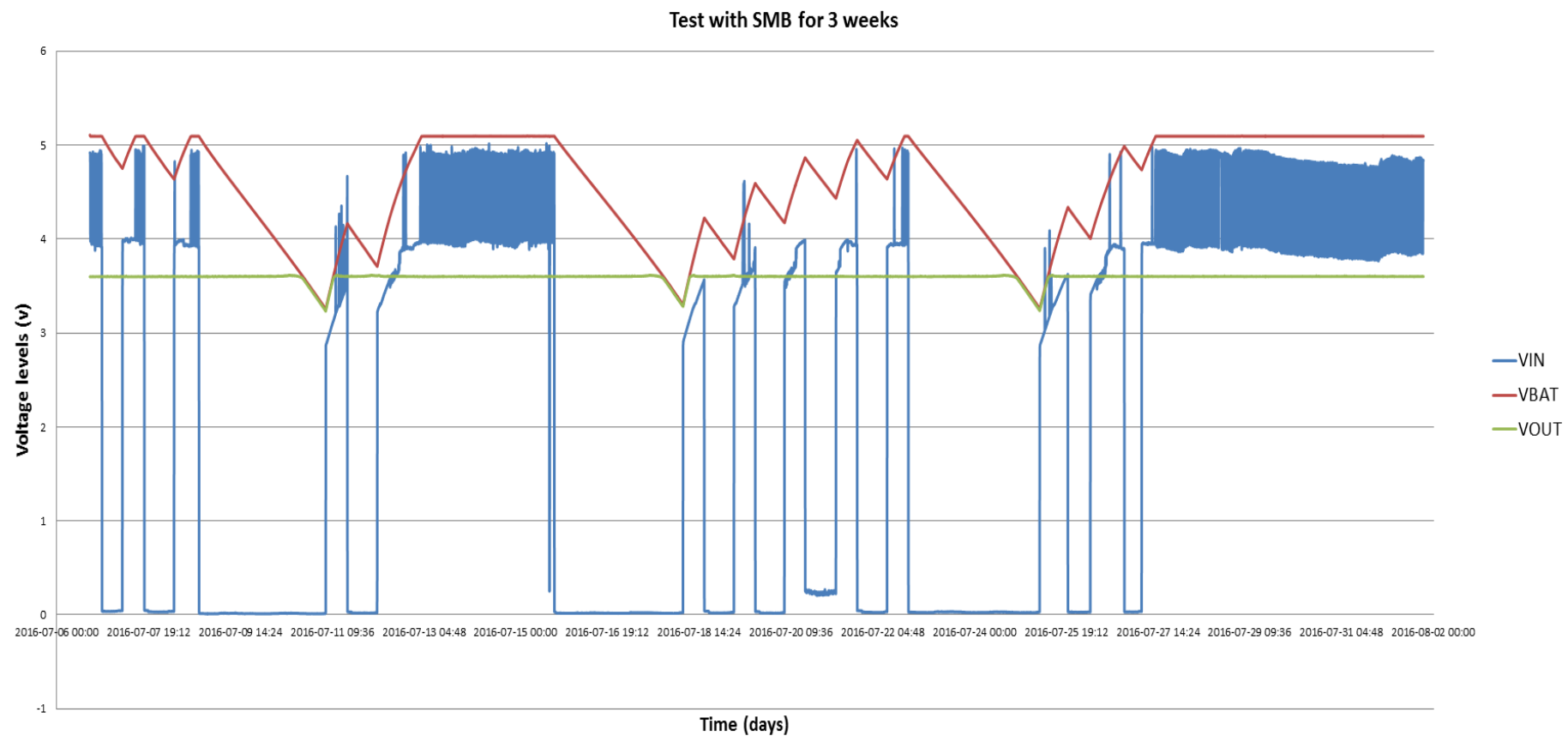

Figure 36. Test with SMB during 3 weeks. 


\section{Discussion}

At the start of this project the concept of Energy Harvesting was viewed in a broad perspective. The aim was to get knowledge of the available methods in an attempt to make the best possible proof of concept. After understanding the different operation modes of the SMB as well as when the external power source was needed, both vibration and heat as energy sources were neglected. RF-harvesting was soon after some studies of literature sources realized that it is still on a research level and not practical at the present time. The only energy source left was solar cells and the proof of concept was design with solar cells as the energy harvester.

As mentioned in section 1.1.1, when the SMB is in Battery mode the highest power consumption of the SMB is $1 \mathrm{~mW}$, meaning that the power consumption can vary depending on what kind of operations that are running but not exceed $1 \mathrm{~mW}$. This can be seen when comparing charge- and discharge-times when using a resistor or the $\mathrm{SMB}$ as the system load. Figures 30 and 31 depict the charge- and discharge-times with a resistor as the system load, where the power consumption was constant at 1 $\mathrm{mW}$. Figures 33 and 34 shows the charge- and discharge-times with the SMB as system load. Charging the supercapacitor bank from 3.6 to $4 \mathrm{~V}$ took $\sim 10$ hours with a resistor as system load, while with the SMB as system load the charging time decreased by more than half of the time, i.e. from 3.7 to $4.1 \mathrm{~V}$ took $\sim 4.8$ hours. Discharging the supercapacitor bank from 5.1 to $3.6 \mathrm{~V}$ took $\sim 25$ hours with a resistor as system load, while with the SMB as system load the discharging time increased nearly 2 times, i.e. from 5.1 to $3.6 \mathrm{~V}$ took $\sim 50$ hours. The only uncertainty of these results is that when measuring the charge- and discharge-times with the SMB the light intensity was $\sim 700$ Lux, while with the resistor as the system load the light intensity was $\sim 600$ Lux.

The theory of Power Management IC states that there are some features that are of importance when designing a PMIC for Energy Harvesting use. The PMIC used in this thesis has the most important ones: The ability to protect the storage element from being completely discharged and unnecessary high charging voltage and the maximum power point tracking algorithm.

In the literature the MPP for solar cells was mentioned to be $80 \%$ of the open circuit voltage. By looking at the graphs in Figures 22-25 it can be shown that all of them have a MPP at around $70-81 \%$, which correspond well with the theory.

The voltage to the SMB has to be constant between 3 and 12 volts, and this was set to $3.6 \mathrm{~V}$ by Equation (27). When there is no available source, i.e. during night, the energy storage has to be used. When the test using the SMB was done for 3 weeks, the largest time when there was no available source was approximately 3 days, which can be seen in Figure 36. However, the supercapacitor bank was designed to last approximately 50 hours as seen in Figure 34. After 50 hours the voltage from the supercapacitor bank decreased below $3.6 \mathrm{~V}$, making the output voltage to the SMB drop to $3.2 \mathrm{~V}$ after 3 
days. This was a problem, because if the voltage to the SMB drops below $3 \mathrm{~V}$ the SMB shuts down. This problem was found at the end of the project and there was no time to further investigate this problem. A potential solution is to connect a boost converter at the output. When the supercapacitor reaches the target voltage (3.6 V) and before the voltage to the SMB drops, the boost converter should step it up to the desired voltage.

Depending on what kind of artificial light is used on the solar cell, different output power is generated. This can be seen in Figures 22-25, where tests on the solar cells are done with LED and Incandescent light under the same conditions. The maximum generated output power of the GaAs PV-cell from Alta Devices with Incandescent light was 1.719 $\mathrm{mW}$, while with LED light the maximum generated output power was $0.2931 \mathrm{~mW}$. The difference is due to the larger radiant spectra from Incandescent light, which confirms the theory from section 2.1.1.1.

Even with the a-Si PV-cell from Panasonic the generated output power is greater with Incandescent light as source compared to LED light. But the difference is not as noteworthy as with the GaAs PV-cell. This is due to the different absorption edge from the PV-cells. As can be seen in Figure 4 the absorption edge for a-SI PV-cells are smaller than those from GaAs PV-cells.

Figure 26 depicts power density as a function of light intensity under LED illumination for the PV-cell from Alta Devices and AM-8801. The light intensities tested on the PVcells were intensities expected of indoor conditions, i.e. 200 - 1000 Lux.

The literature studies show that temperature has a great impact on the output power of the PV-cells. This can be seen in Figure 28 where the power density at $25^{\circ} \mathrm{C}$ was 26.34 $\mathrm{mW} / \mathrm{cm}^{2}, 24.47 \mathrm{~mW} / \mathrm{cm}^{2}$ at $40{ }^{\circ} \mathrm{C}$ and $22.18 \mathrm{~mW} / \mathrm{cm}^{2}$ at $55^{\circ} \mathrm{C}$. An increase of the temperature from 25 to $40{ }^{\circ} \mathrm{C}$ decreases the maximum output power by $7.1 \%$.

The bill of material in section A.2 includes only the cost for the PCB. The cost of solar cells and supercapacitors was not included due to the various types and costs of these, as well as supercapacitors should be chosen depending on the ambient where the ABB robot is installed. The cost of the PCB was 192 Swedish kronor, this value would decrease if the electrical component were bought by ABB in a large quantity. 


\subsection{Conclusion}

This Master Thesis focuses on the development of an Energy Harvesting system for usage in indoor environment. The energy harvester, i.e. the solar panel, had to efficiently transfer the energy generated to the storage element and the system load. This was achieved with the help of a PMIC. Main issue with solar as Energy Source is the inconsistency of energy and the low availability of power.

The established goals were successfully reached in this thesis where the following tasks were completed:

- Research and study the Energy Harvesting methods, and analyze their characteristics and performance in order to select the most appropriate one for supplying power to the SMB.

- Compare the difference between rechargeable batteries and supercapacitors, and which one is most appropriate in an Energy Harvesting System.

- Research PMICs available in the market at the moment, and provide an accurate study of the functionality of the PMIC used in this Master Thesis.

- Design an Energy Harvesting System with at least one of the methods in the literature study, and design a schematic of the prototype as well as drawing the PCB layout and solder electrical component to the PCB.

- Measurements and characterization of two industrial solar cells, provides more information than what is possible to get from manufacturers datasheets. The same measurement approach can be used to reproduce all the experiments. This is thanks to in-depth explanations.

- Charge- and discharge-times of the supercapacitor bank and test with the whole Energy Harvesting System.

This thesis achieved the intent to bring knowledge and learning in ABB in order to help the work of others employees to develop future products. 


\subsection{Future work}

This thesis demonstrates that it is possible to power the SMB with an output power generated by an energy harvester of PV-cells, under the specified conditions. A recommendation when using energy harvesting is to make sure that the energy stored will last during absence of any energy source, but in the future perspective, there could be further studies such as:

- The possibility to use a hybrid solution, meaning that both an Energy Harvesting method and rechargeable batteries can be used. How much this could expand the life time of the rechargeable battery?

- Taking into account the effect on solar panels when exposed to shading. How much does this effect the power output of series- as well as parallel-connected solar cells?

- Do a more accurate calculation on how much actually could be saved in terms if real money, if the replacements of batteries in ABB robots were substituted with solar as Energy Harvesting method. 
[1] M. T. Kibria, A. Ahmmed, S. M. Sony and F. H. Shams-UI-Islam, "A Review: Comparative studies on different generation solar cells technology", 2014. [Online]. Available:

http://benjapan.org/ICEAB/proceedingsICEAB14/i14\%20p33.pdf. [Accessed 0610 2016].

[2] A. Khaligh and O. C. Onar, "Energy harvesting solar, wind, and ocean energy conversion systems", 2010, ISBN: 978-1-4398-1508-3. [Online]. Available: https://www.crcpress.com/Energy-Harvesting-Solar-Wind-andOcean-Energy-Conversion-Systems/Khaligh-Onar/p/book/9781439815083. [Accessed 0610 2016].

[3] W. D. Silva, "Milestone in solar cell efficiency by UNSW engineers", 2016. [Online]. Available: http://newsroom.unsw.edu.au/news/science-tech/milestone-solar-cell-efficiency-unswengineers. [Accessed 0610 2016].

[4] I. Mathews, G. Kelly and P. J. King, "GaAs solar cells for Indoor Light Harvesting", 2014. [Online]. Available: http://ieeexplore.ieee.org/document/6924971/. [Accessed 0610 2016].

[5] I. Mathews, P. J. King, F. Stafford and R. Frizzeli, "Performance of III-V Solar Cells as Indoor Light Energy Harvesters", 2015. [Online]. Available: http://ieeexplore.ieee.org/document/7307101/. [Accessed 0610 2016].

[6] M. A. Green, K. Emery, Y. Hishikawa, E. D. Dunlop and W. Warta, "Solar cell efficiency tables (version 48)", 2016. [Online]. Available: http://onlinelibrary.wiley.com/doi/10.1002/pip.2788/full. [Accessed 0610 2016].

[7] "GCell by G24 Power", 2016. [Online]. Available: http://gcell.com/knowledge-hub/solar-cells. [Accessed 0610 2016].

[8] "Solar Energy For Us", 2016. [Online]. Available: http://solarenergyforus.com/solar-panel-efficiency-lifespan/. [Accessed 0610 2016].

[9] "ALTERNATIVE ENERGY TUTORIALS", 2016. [Online]. Available: http://www.alternative-energytutorials.com/energy-articles/solar-cell-i-v-characteristic.html . [Accessed 0610 2016].

[10] Y. K. Tan, "Energy Harvesting Autonomous Sensor Systems", 2013, ISBN: 978-1-4398-9273-2. [Online]. Available: https://www.crcpress.com/Energy-Harvesting-Autonomous-Sensor-Systems-DesignAnalysis-and-Practical/Tan/p/book/9781439892732. [Accessed 0610 2016].

[11] S. P. Beeby and T. O'Donnell, "Electromagnetic Energy Harvesting", 2009, ISBN: 978-0-387-76463-4. [Online]. Available: http://link.springer.com/chapter/10.1007\%2F978-0-387-76464-1_5. [Accessed 0610 2016]. 
[12] "History of piezoelectricity", [Online]. Available: http://www.piezo.com/tech4history.html. [Accessed 0610 2016].

[13] P. Spies, M. Pollak and L. Mateu, "Handbook of Energy Harvesting Power Supplies and Applications", 2015, ISBN: 978-981-4241-86-1. [Online]. Available: https://www.crcpress.com/Handbook-of-Energy-HarvestingPower-Supplies-and-Applications/Spies-Pollak-Mateu/p/book/9789814241861. [Accessed 0610 2016].

[14] M. Deepam, Y. Yongke and P. Shashank, "Advanced Materials for Clean Energy", 2015, ISBN: 978-1-48220578-7. [Online]. Available: http://www.crcnetbase.com/doi/abs/10.1201/b18287-6. [Accessed 0610 2016].

[15] D. Nemir and J. Beck, "On the Significance of the Thermoelectric Figure of Merit Z", 2010. [Online]. Available: http://link.springer.com/article/10.1007/s11664-009-1060-4. [Accessed 0610 2016].

[16] J. G. Snyder, "Small Thermoelectric Generators", 2008. [Online]. Available: https://www.electrochem.org/dl/interface/fal/fal08/fal08_p54-56.pdf. [Accessed 0610 2016].

[17] "PTS Inriktningsplan för spektrumhantering", 2015. [Online]. Available: https://www.pts.se/upload/Ovrigt/Radio/inriktningsplan-spektrumhantering-151002.pdf. [Accessed 0610 2016].

[18] H. T. Friis, "A Note. on a Simple Transmission Formula", 1946. [Online]. Available: http://ieeexplore.ieee.org.ludwig.lub.lu.se/stamp/stamp.jsp?arnumber $=1697062 \&$ tp $=\&$ tag $=1$. [Accessed 06 10 2016].

[19] M. Piñuela, P. D. Mitcheson and S. Lucyszyn, "Ambient RF Energy Harvesting in Urban and Semi-Urban Environments", 2013. [Online]. Available: http://ieeexplore.ieee.org/document/6519964/. [Accessed 0610 2016].

[20] "Tips to Getting the Most Out of Energy Harvesting Sources", 2016. [Online]. Available: http://www.digikey.com/en/articles/techzone/2016/apr/tips-to-getting-the-most-out-of-energy-harvestingsources. [Accessed 0610 2016].

[21] D. Freeman, "Introduction to Photovoltaic Systems Maximum Power Point Tracking", 2010. [Online]. Available: http://www.ti.com/lit/an/slva446/s/va446.pdf. [Accessed 0610 2016].

[22] "The Cell Potential", 2015. [Online]. Available: http://chem.libretexts.org/Core/Analytical_Chemistry/Electrochemistry/Voltaic_Cells/The_Cell_Potential. [Accessed 0610 2016].

[23] "Standard Reduction Potentials (in Volts), 25oC", [Online]. Available: http://www.csudh.edu/oliver/chemdata/data-e.htm. [Accessed 0610 2016].

[24] S. Mitchell, "Electrochemical Processes in Batteries", 2015. [Online]. Available: http://slideplayer.com/slide/4611740/. [Accessed 0610 2016]. 
[25] "Electropaedia - Battery Performance Characteristics", [Online]. Available:

http://www.mpoweruk.com/performance.htm. [Accessed 0610 2016].

[26] M. S. Halper and J. C. Ellenbogen, "Supercapacitors: A Brief Overview", 2006. [Online]. Available: https://www.mitre.org/sites/default/files/pdf/06_0667.pdf. [Accessed 0610 2016].

[27] Xoneca, "Wikipedia", 2014. [Online]. Available: https://en.wikipedia.org/wiki/Supercapacitor\#/media/File:Supercapacitor_types_overview.svg. [Accessed 06 $102016]$

[28] C. Simpson, "Characteristics pf rechargeable batteries", 2011. [Online]. Available: http://www.ti.com/lit/an/snva533/snva533.pdf. [Accessed 0610 2016].

[29] "Diffen - Li-ion vs. NiCad", 2013. [Online]. Available: http://www.diffen.com/difference/Li-ion_vs_NiCad. [Accessed 0610 2016].

[30] H. Yang, S. Kannappan, A. S. Pandian, J.-H. Jang, Y. S. Lee and W. Lu, "Achieving Both High Power and Energy Density in Electrochemical Supercapacitors with Nanoporous Graphene Materials", 2013. [Online]. Available: https://arxiv.org/pdf/1311.1413v1.pdf. [Accessed 0610 2016].

[31] "Battery University - BU-209: How does a Supercapacitor Work?", 2016. [Online]. Available: http://batteryuniversity.com/learn/article/whats_the_role_of_the_supercapacitor. [Accessed 0610 2016].

[32] "bq25570 Nano Power Boost Charger and Buck Converter for Energy Harvester Powered Applications", 2015. [Online]. Available: http://www.ti.com/lit/ds/slusbh2e/slusbh2e.pdf. [Accessed 0610 2016].

[33] "Bussmann by Eaton", 2011. [Online]. Available: http://www.cooperindustries.com/content/dam/public/bussmann/Electronics/Resources/productdatasheets/bus-elx-ds-4403-phv-series.pdf. [Accessed 0610 2016]. 


\section{Appendices}

A.1 Schematic of the PCB

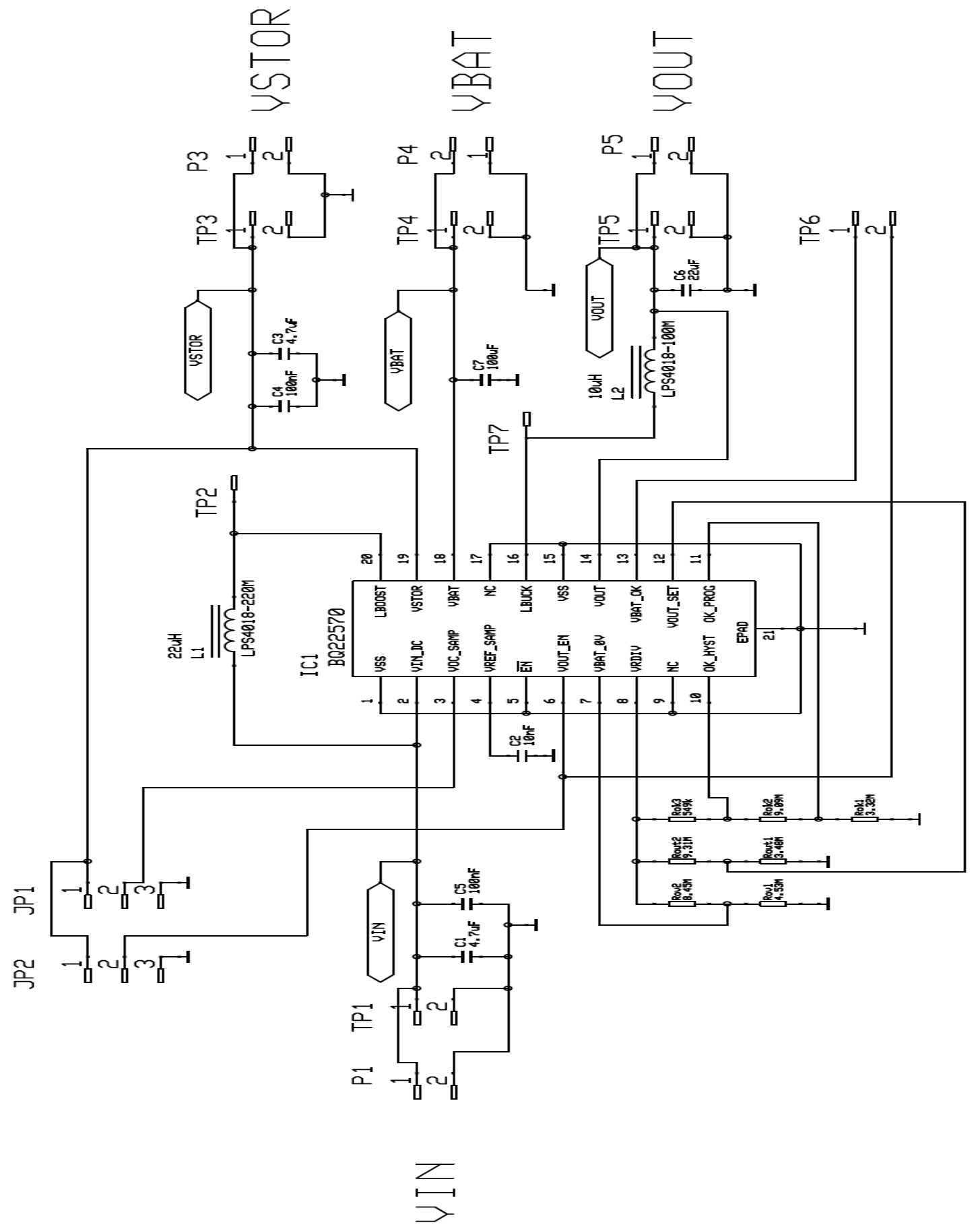

Figure 37. Schematic of the prototype. 
Figure 37 depicts the pins of the BQ25570 IC and the different electrical component connected to them. At VIN the solar panel is connected, at VBAT the supercapacitor bank is connected and at VOUT the system, i.e. the SMB, is connected.

\section{A.2 Bill of Materials for PCB}

Table 8. Bill of materials for PCB.

\begin{tabular}{|c|c|c|c|c|c|c|c|c|c|c|c|c|c|c|c|c|c|c|c|}
\hline 施 & $\begin{array}{l}\mathbf{\Delta} \\
\mathbf{\sigma}\end{array}$ & 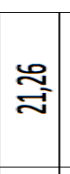 & 营 & $\stackrel{8}{\circ}$ & క్ & 岩 & 录 & 吢 & : & 吢 & 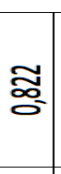 & 急 & $\stackrel{\infty}{\stackrel{9}{9}}$ & $\frac{E}{F}$ & $\stackrel{8}{9}$ & 学 & $\underset{m}{\infty}=$ & $\bar{r}$ & \\
\hline 譥 & 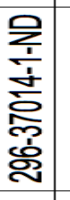 & 总 & 总 & $\begin{array}{l}\text { 总 } \\
\text { 㝏 }\end{array}$ & $\begin{array}{l}\text { : } \\
\text { ఫ్ }\end{array}$ & 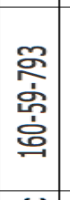 & 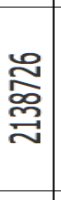 & $\begin{array}{l}\text { 禀 } \\
\text {. }\end{array}$ & 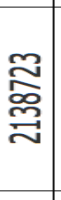 & 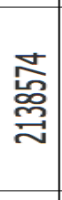 & 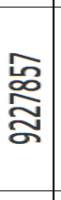 & $\begin{array}{l}\text { : } \\
\text { : } \\
\text { : }\end{array}$ & $\begin{array}{l}\text { 莟 } \\
\underset{\Xi}{二}\end{array}$ & $\begin{array}{l}\widetilde{\widetilde{8}} \\
\text { : }\end{array}$ & 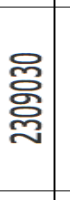 & $\begin{array}{l}\text { 范 } \\
\text { 帘 }\end{array}$ & 象 & 象 & \\
\hline 讋 & 唁 & $\mid$\begin{tabular}{|l}
$\overline{\overline{\underline{\underline{m}}}}$ \\
$\overline{\underline{w}}$
\end{tabular} & $\begin{array}{l}\overline{\bar{E}} \\
\text { 空 }\end{array}$ & 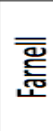 & 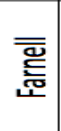 & 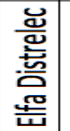 & 离 & 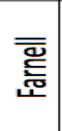 & 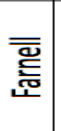 & 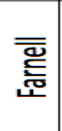 & 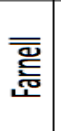 & 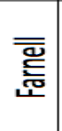 & 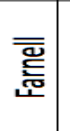 & 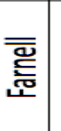 & 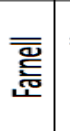 & 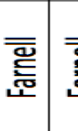 & 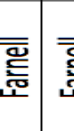 & 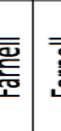 & \\
\hline 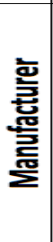 & $F$ & 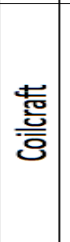 & $\begin{array}{l}\text { 芴 } \\
\end{array}$ & 跑 & 善 & 咅 & 产 & 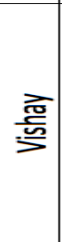 & 言 & $\begin{array}{l}\frac{\mathbf{a}}{\mathbf{0}} \\
\frac{5}{5}\end{array}$ & 訔 & 裹 & 誉 & 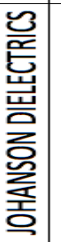 & 首 & 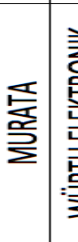 & & 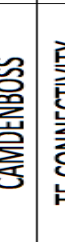 & 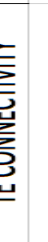 \\
\hline$\approx$ & 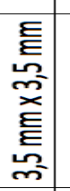 & 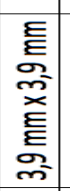 & 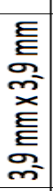 & $\approx$ & $\tilde{8}$ & $\%$ & 8 & $\tilde{3}$ & 8 & 80 & 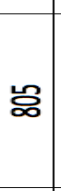 & $\tilde{3}$ & 岁 & 8̂. & 岁 & ్్ㅁ & 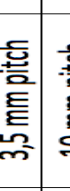 & 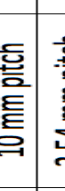 & 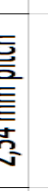 \\
\hline 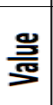 & & 急 & 甹 & 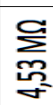 & 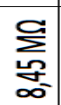 & $\sum_{j}^{q}$ & 璦 & 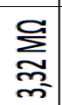 & 愛 & $\begin{array}{l}\text { 帘 } \\
\text { 善 }\end{array}$ & 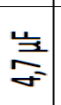 & 言 & 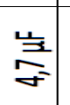 & 旁 & 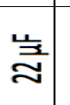 & 言 & & & \\
\hline 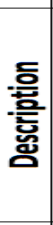 & 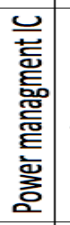 & $\mid \begin{array}{l}\text { 흘 } \\
\text { 흘 }\end{array}$ & 㝬 & 蒿 & 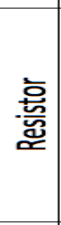 & 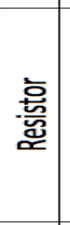 & 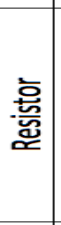 & 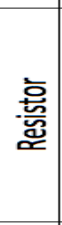 & $\begin{array}{l}\text { 妾 } \\
\text { 妾 }\end{array}$ & 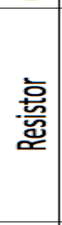 & 흘응 & $\begin{array}{l}\text { 흥 } \\
\text { 잉 }\end{array}$ & $\begin{array}{l}\overline{\mathrm{z}} \\
\text { 莺 }\end{array}$ & 言 & 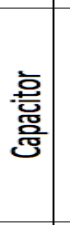 & 产 & 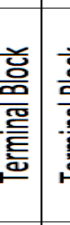 & 童 & 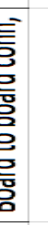 \\
\hline 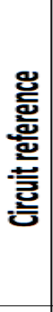 & 窎 & $\exists$ & $\simeq$ & 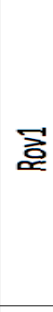 & 호 & 言 & 㐔 & 景 & 童 & 旁 & ( & 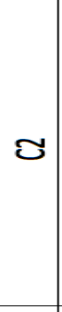 & 3 & 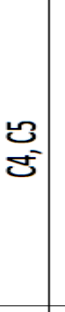 & 8 & 0 & 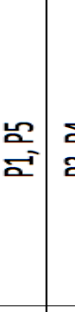 & 竞 & 琹 \\
\hline $\begin{array}{l}\text { 垔 } \\
\text { 言 }\end{array}$ & $\rightarrow$ & & - & $\rightarrow$ & $\neg$ & & -1 & & $\rightarrow$ & & $\rightarrow$ & & $\rightarrow$ & $\sim$ & & & $\sim$. & $\sim$ & \\
\hline
\end{tabular}

Table 8 gives the complete bill of material for the PCB. The total cost landed on 191.41 Swedish kronor. 


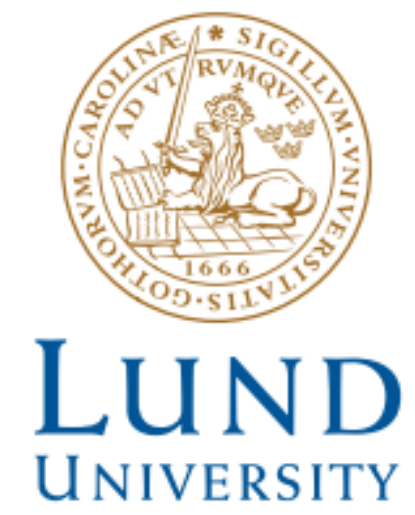

